\title{
Imaging air volume fraction in sea ice using non-destructive $X$-ray tomography
}

\author{
Odile Crabeck $^{1}$, Ryan Galley ${ }^{1}$, Bruno Delille ${ }^{2}$, Brent Else ${ }^{3}$, Nicolas-Xavier Geilfus ${ }^{1}$, Marcos Lemes ${ }^{1}$, \\ Mathieu Des Roches ${ }^{5}$, Pierre Francus ${ }^{5}$, Jean-Louis Tison ${ }^{6}$, and Søren Rysgaard ${ }^{1,4,7}$ \\ ${ }^{1}$ Department of Geological Sciences, Centre for Earth Observation, University of Manitoba, Winnipeg, Manitoba, Canada \\ ${ }^{2}$ Unité d'Océanographie Chimique, MARE, Université de Liège, Liège, Belgium \\ ${ }^{3}$ Department of Geography, University of Calgary, Calgary, Alberta, Canada \\ ${ }^{4}$ Arctic Research Centre, Aarhus University, Aarhus, Denmark \\ ${ }^{5}$ Centre Eau terre et Environement, INRS-Été-Quebec, Quebec, Canada \\ ${ }^{6}$ Laboratoire de Glaciologie, DSTE, Université Libre de Bruxelles, Bruxelles, Belgium \\ ${ }^{7}$ Greenland Climate Research Centre, Greenland Institute of Natural Resources, Nuuk, Greenland
}

Correspondence to: Odile Crabeck (crabecko@myumanitoba.ca)

Received: 13 August 2015 - Published in The Cryosphere Discuss.: 30 September 2015

Revised: 2 March 2016 - Accepted: 25 April 2016 - Published: 27 May 2016

\begin{abstract}
Although the presence of a gas phase in sea ice creates the potential for gas exchange with the atmosphere, the distribution of gas bubbles and transport of gases within the sea ice are still poorly understood. Currently no straightforward technique exists to measure the vertical distribution of air volume fraction in sea ice. Here, we present a new fast and non-destructive X-ray computed tomography technique to quantify the air volume fraction and produce separate images of air volume inclusions in sea ice. The technique was performed on relatively thin $(4-22 \mathrm{~cm})$ sea ice collected from an experimental ice tank. While most of the internal layers showed air volume fractions $<2 \%$, the ice-air interface (top $2 \mathrm{~cm}$ ) systematically showed values up to $5 \%$. We suggest that the air volume fraction is a function of both the bulk ice gas saturation factor and the brine volume fraction. We differentiate micro bubbles $(\varnothing<1 \mathrm{~mm})$, large bubbles ( $1 \mathrm{~mm}<\varnothing<5 \mathrm{~mm})$ and macro bubbles $(\varnothing>5 \mathrm{~mm})$. While micro bubbles were the most abundant type of gas bubbles, most of the air porosity observed resulted from the presence of large and macro bubbles. The ice texture (granular and columnar) as well as the permeability state of ice are important factors controlling the air volume fraction. The technique developed is suited for studies related to gas transport and bubble migration.
\end{abstract}

\section{Introduction}

Sea ice is a multi-phase system consisting of ice crystals, salt precipitates, brine, and gas bubbles (i.e., air inclusions). The abundance and morphology of brine and air inclusions are strongly dependent on the temperature and salinity of the sea ice (Cox and Weeks, 1983; Weeks and Ackley, 1986). Microscale studies of sea ice inclusions have in large part focused on the formation and morphology of brine inclusions (as pockets and/or channels) (e.g., Bennington, 1967; Bock and Eicken, 2005; Cole and Shapiro, 1998; Cox and Weeks, 1975; Eicken et al., 2000; Eide and Martin, 1975; Galley et al., 2015; Hunter et al., 2009; Notz and Worster, 2008). Inclusions in large part control the transfer of heat, salt, gases, and radiation between the ocean and atmosphere (Light et al., 2003). Brine and air inclusions in sea ice also affect the optical and electromagnetic properties of sea ice, and are often sites of biological activity (Fritsen et al., 1994; Krembs et al., 2000; Vancoppenolle et al., 2013).

Studies on the formation and morphology of gas inclusions and gas transport within sea ice are sparse. The air porosity quantitatively defined by the air volume fraction $\left(V_{\mathrm{a}} \%\right)$ has generally been neglected in past work; it has long been assumed that gas species in sea ice were dissolved in brine and subject to the same processes as brine inclusions, and that the air volume fraction is minor compared to the brine 
volume fraction. Mushy layer theory, whose equations are now used as the physical basis for liquid exchange processes within sea ice neglect the presence of air inclusions (Feltham et al., 2006; Worster, 1992, 1997; Rees Jones and Worster, 2013). Omission of air inclusions in sea ice research propagates a lack of understanding of gas transport within sea ice, though studies in the last decade have revealed substantial $\mathrm{CO}_{2}$ fluxes at the sea-ice-atmosphere interface (Semiletov et al., 2004; Zemmelink et al., 2006; Delille et al., 2014; Geilfus et al., 2014, 2015; Normura et al., 2006, 2010, 2014). It was also recently argued that a major part of the natural gases (oxygen, nitrogen, and argon) as well as methane $\left(\mathrm{CH}_{4}\right)$ resides in the gas phase inside bubbles in sea ice rather than dissolved in the brine (Zhou et al., 2013; Moreau et al., 2014; Crabeck et al., 2014a, b). Therefore the physical properties and processes of air inclusions in sea ice can potentially control the sea-ice-atmosphere exchange of gases. The most important process leading to the formation of air inclusions from entrapped brine is brine volume reduction by freezing (Zhou et al., 2013; Crabeck et al., 2014a, b; Moreau et al., 2014). Increasing brine salinity during winter due to sea ice temperature reduction results in reduced gas solubility causing super-saturation (the brine concentration effect), which leads to bubble formation if the sum of the partial pressures of all the dissolved gases is higher than the local hydrostatic pressure.

Previous studies of air inclusions morphology in sea ice were based on horizontal thin sections (e.g., Grenfell, 1983; Perovich and Gow, 1991, 1996; Light et al., 2003; Cole et al., 2004). Grenfell (1983), Perovich and Gow (1996) and Cole et al. (2004) highlighted that the columnar ice is usually depleted in air inclusions while top granular ice is described as bubbly with larger air inclusions. Grenfell (1983) measured bubble number distributions in small samples cut from first year sea ice, observing diameters ranging from 0.2 to $4 \mathrm{~mm}$. Perovich and Gow (1996) reported mean bubble diameters ranging from 0.036 to $0.56 \mathrm{~mm}$ for $30 \mathrm{~cm}$-thick pancake ice and mean diameter of $2.6 \mathrm{~mm}$ on a multi-year hummock. Light et al. (2003) recorded 100 images from thin sections in transmitted light and reported bubble diameters between 0.008 to $0.14 \mathrm{~mm}$ in ice columnar ice that was $175 \mathrm{~cm}$ thick (Light et al., 2003).

Limitations of current methods have resulted in a lack of details on determination of air volume fraction. Those methods provide inadequate profiles of the vertical distribution of air inclusions in sea ice, especially in the context of oceansea-ice atmosphere exchange of gas. The sea ice air volume fraction is most often determined empirically from bulk temperature, salinity and density measurements (after Cox and Weeks, 1983). However, small errors associated with sea ice density measurements result in large errors in the calculated air volume fraction. Perovich and Gow (1996), and Light et al. (2003) used sea ice sections imaged using transmitted light to describe air inclusions within sea ice, given the caveats that undisturbed microstructure required careful ther- mal control, size may be limited, and the distinction between gas and brine can be ambiguous in transmitted images. While thin section studies are relevant to detail morphometric analysis of inclusions, profile of air volume fraction cannot be deduced from thin section analysis. Another approach is high resolution measurements of the total gas content along a vertical profile using techniques initially developed for continental ice cores (melting-refreezing and toepler pump extraction or summing individual gases concentrations measured using gas chromatography (GC); Tison et al., 2002). These techniques however operate under vacuum, and therefore collect both the dissolved and gaseous phases. Also, this technique does not provide information on the morphology of the bubble content. A third approach used previously is to melt the ice sample in a gas tight container and quantify total gas volume (Rysgaard and Glud, 2004). A problem with this approach, however, is that gases equilibrate to a new bulk gas concentration depending on the salinity and temperature of the melting ice and hence do not represent the actual gas volume at in situ conditions.

We propose a methodological advancement employing computed tomography (CT) X-ray imaging for measurement of air inclusions within sea ice. For many years CT X-ray has been widely used as a medical diagnostic tool. This noninvasive technique has largely contributed to the study of rock fractures and rock porosity, and has recently been applied to the sea ice field, advancing percolation theory for the brine system (Golden et al., 2007; Pringle et al., 2009, Obbard et al., 2009). Here we present high-resolution profiles of the distribution of air inclusions in sea ice, which are derived from CT X-ray images of whole ice cores at the sub-millimeter scale. A detailed statistical analysis of the air volume fraction in experimental sea ice is presented, as well as comparisons to the air volume equations of Cox and Weeks (1983) and measurement of total gas content. Throughout this work, we highlight the parameters and processes influencing the air porosity (air volume fraction, $V_{\mathrm{a}}$ ).

\section{Methods}

\subsection{Sea-ice Environmental Research Facility (SERF)}

The Sea-ice Environmental Research Facility (SERF) at the University of Manitoba (Winnipeg, Canada) is an in-ground concrete pool with dimensions of $23.3 \mathrm{~m}$ (length) $\times 9.2 \mathrm{~m}$ (width) $\times 2.75 \mathrm{~m}$ (depth). It is filled each year with seawater formulated on site to closely replicate the chemistry of Arctic surface seawater (e.g., Hare et al., 2013; Geilfus et al., 2013; Rysgaard et al., 2014). In January 2013 an experiment was initiated from open water conditions, where sea ice was allowed to grow to $22 \mathrm{~cm}$ thick between 13 and 26 January. Ice cores were collected on 14, 16 and 25 January to measure bulk ice gas composition, temperature, salinity, and density, and for computed tomography (CT) X-ray imaging. 
Table 1. Effect of dimensional error on brine volume and air volume fraction computed by mass-volume density measurement using state equation from Cox and Weeks (1983).

\begin{tabular}{lcclcccc}
\hline $\begin{array}{l}\text { Temperature } \\
\left({ }^{\circ} \mathrm{C}\right)\end{array}$ & Salinity & $\begin{array}{c}\text { Length } \\
(\mathrm{cm})\end{array}$ & $\begin{array}{l}\text { Ice cube } \\
\text { volume } \\
\left(\mathrm{cm}^{3}\right)\end{array}$ & $\begin{array}{c}\text { Masse } \\
(\mathrm{g})\end{array}$ & $\begin{array}{l}\text { Density } \\
\left(\mathrm{g} \mathrm{cm}^{3}\right)\end{array}$ & $\begin{array}{c}V_{\mathrm{b}} \\
(\%)\end{array}$ & $\begin{array}{l}V_{\mathrm{a}} \\
(\%)\end{array}$ \\
\hline-5.00 & 5.00 & 4.93 & 119.82 & 113.75 & 0.95 & 5.1 & -1.3 \\
-5.00 & 5.00 & 5.00 & 125 & 113.75 & 0.91 & 4.9 & 2 \\
-5.00 & 5.00 & 5.07 & 130.32 & 113.75 & 0.87 & 4.7 & 6.3 \\
\hline $\begin{array}{l}\text { Relative standard } \\
\text { error }\end{array}$ & & $\pm 1.4 \%$ & $\pm 4.2 \%$ & & $\pm 4.4 \%$ & $\pm 4.1 \%$ & $\pm 163 \%$ \\
\hline
\end{tabular}

\subsection{Sea ice core: temperature, salinity and texture}

At least four ice cores were extracted on each sampling occasion using a Mark II core barrel with an internal diameter of $9 \mathrm{~cm}$ (Kovacs Ent., Lebanon NH, USA). One of the cores was destructively interrogated to measure an in situ ice temperature profile at a depth resolution of $2 \mathrm{~cm}$ using a calibrated probe (Testo 720 , precision $\pm 0.1^{\circ} \mathrm{C}$ ) inserted into pre-drilled holes perpendicular to the ice core depth axis. The second ice core extracted was immediately cut into $2 \mathrm{~cm}$ slices, which were stored in polyethylene buckets and left to melt close to $0^{\circ} \mathrm{C}$. Bulk ice salinity of the melt of these $2 \mathrm{~cm}$ sections was derived from sample conductivity and temperature measured with an Orion Star Series WP-84TP conductivity meter (precision \pm 0.1 ) using the equations of Grasshoff et al. (1983). For sea ice gas content and CT X-ray imaging, the third and fourth cores were immediately wrapped in polyethylene bags and stored at $-20^{\circ} \mathrm{C}$ in the dark to ensure brine/gas immobilization and to inhibit biological processes (Eicken et al., 1991).

\subsection{Gas composition}

The bulk ice concentration of argon (Ar), oxygen $\left(\mathrm{O}_{2}\right)$ and nitrogen $\left(\mathrm{N}_{2}\right)$ expressed in $\mu \mathrm{mol} \mathrm{L}-1$ ice were analyzed using gas chromatography (GC). The dry-crushing technique as developed for gas measurements in continental ice (e.g., Raynaud et al., 1982) was used to extract the gas phase from the sea ice samples in a cold laboratory at $-25^{\circ} \mathrm{C}$. Each ice core sample for gas composition was cut in $5 \mathrm{~cm}$ sections, and $60 \mathrm{~g}$ of each section were put into a vessel together with stainless steel beads which was evacuated to $10^{-3}$ torr, and then fixed to an ice crusher (after Raynaud et al., 1982 and Stefels et al., 2012). The stainless steel beads impact the ice block during the shaking process, crushing it into a fine powder. After crushing, the vessel was kept in a cold ethanol bath $\left(-50^{\circ} \mathrm{C}\right)$ and connected to a gas chromatograph (Trace GC) equipped with a thermal conductivity detector for concentration analyses (Skoog et al., 1997). We used AlphagazTM2 $\mathrm{He}$ (Air Liquid - P0252) as the carrier gas and a $22 \mathrm{ml}$ packed column (Mole Sieve 5A 80/100; $\left.5 \mathrm{~m} \times 1 / 8^{\prime \prime}\right)$. Gas collected included both gas bubbles in the ice and from the dissolved phase within the brine, which cannot be differentiated using this method. The total gas content $\left(\mathrm{mLL}^{-1}\right.$ ice) was derived from the sum of the $\mathrm{O}_{2}, \mathrm{~N}_{2}$ and Ar concentrations initially expressed in $\mu \mathrm{mol} \mathrm{L}^{-1}$ ice and applying the ideal gas law. Since both the cutting process and evacuation stage during the measurement process lead to potential gas lost, the total gas content measured is a minimum estimate of the true total gas content.

The saturation level of a gas affects bubble nucleation in brine inclusions and is therefore a crucial parameter determining gas flux at the ice-air interface. Theoretically, nucleation occurs when the sum of the partial pressures of dissolved gases is higher than the local hydrostatic pressure. We therefore compared (i) the gas concentrations profile measured in bulk ice; $C_{\text {bulkice }}$ to (ii) the theoretical inventory predicted by the solubility in brine at atmospheric saturation; $C_{\text {Saturation }}$ (i.e., the maximum concentration of $\mathrm{O}_{2}, \mathrm{~N}_{2}$ and $\mathrm{Ar}$ in the dissolved phase when the brine is not supersaturated; Carte, 1961; Lubetkin, 2003; Zhou et al., 2013). $C_{\text {Saturation }}$ is obtained by calculating the temperature and salinity-dependent solubility of $\mathrm{O}_{2}, \mathrm{~N}_{2}$ and $\mathrm{Ar}$ in the brine (Garcia and Gordon, 1992; Hamme and Emerson, 2004) and multiplying it by the relative brine volume (i.e., the brine volume fraction $\left(V_{\mathrm{b}}\right)$, see below) and expressed in $\mathrm{mLL}^{-1}$ of bulk ice. These relationships are valid for the range of temperature and salinity found in sea ice (Zhou et al., 2013). It is important to note that as $C_{\text {bulk ice }}$ is measured on $5 \mathrm{~cm}$ ice sections while $C_{\text {saturation }}$ is computed using $2 \mathrm{~cm}$ sections, we

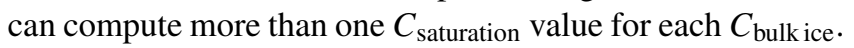
The ratio between the gas concentration measured ( $\left.C_{\text {bulk ice }}\right)$ and the air concentration at equilibrium $\left(C_{\text {saturation }}\right)$ gives the saturation factor $\mathrm{SAT}_{\mathrm{f}}$ : as a result, we present the mean $\mathrm{SAT}_{\mathrm{f}}$ and its standard deviation for each $C_{\text {bulk ice }}(5 \mathrm{~cm})$ section. When a strong gradient of temperature, salinity, and therefore brine volume occurs in a $C_{\text {bulk ice }} 5 \mathrm{~cm}$ section, the standard deviation of $\mathrm{SAT}_{\mathrm{f}}$ increases. 


\subsection{Bulk ice density and air volume fraction}

To compute the brine volume fraction and the air volume fraction, the bulk ice density of $5 \mathrm{~cm}$ core sections was measured with the mass-volume technique in a cold lab $\left(-20^{\circ} \mathrm{C}\right)$, and the Cox and Weeks (1983) equations were then employed. Ice core sections were cut into cubes of $5 \mathrm{~cm}^{3}$ and weighed precisely to determine their mass $(M)$. The dimensions of the sample were measured giving their volume $(V)$. The density of the ice $\left(\rho_{\mathrm{i}}\right)$ calculated by

$\rho_{\mathrm{i}}=\frac{M}{V}$

This common technique is easily applied, but there are several possible sources of errors: obtaining a dimensionally perfect ice sample is difficult, and inaccuracies in the measurement of the sample dimensions lead to volume error (Timco and Frederking, 1996).

To limit error induced by imperfect sample dimensions, we used a precision diamond wire saw. The length of each edge (the number of edges per cube $=12$ ) was found to deviate from $5 \mathrm{~cm}$ by $\pm 0.07 \mathrm{~cm}$ on average (total number of edges measured $=96 ; 8$ ice cubes) yielding an average precision for ice density of $\pm 4.4 \%$, as a result of the cutting process. While deviation of $0.7 \mathrm{~mm}$ on the dimension of the ice cube has little effect on the precision of the density and of the calculated brine volume fraction (relative standard error $<5 \%$ ), it produces relative standard errors as high as $163 \%$ on the air volume fraction computed using the equations of Cox and Weeks (1983) (Table 1).

\subsection{Liquid porosity: brine volume fraction}

The brine volume was calculated according to Cox and Weeks (1983) using in situ temperature, bulk ice salinity, and bulk ice density measurements from the cores. Brine salinity $\left(S_{\mathrm{b}}\right)$ was calculated using in situ sea ice temperatures and the freezing point of seawater (UNESCO, 1978). The brine volume fraction, $\left(V_{\mathrm{b}}\right.$, expressed in $\%$ ), was calculated from the ratio of brine volume and bulk sea ice volume $(b / V)$. In previous works, sea ice air volume fraction is ubiquitously neglected, so historically, sea ice porosity refers solely to the brine volume fraction. In the context of this paper, the terms brine inclusions and brine volume fraction refers to liquid porosity. The permeability threshold of $V_{\mathrm{b}}=5 \%$ following Golden et al. (1998, 2007) defines permeable and impermeable columnar sea ice.

\subsection{Ice texture}

To describe the ice crystal texture, horizontal thin sections of maximum $10 \mathrm{~cm}$ length were produced in a cold lab at $-20^{\circ} \mathrm{C}$ using the standard microtome (Leica SM2400) procedure described by Langway (1958) and Tison et al. (2008). Images of these backlit horizontal thin sections were taken in the cold lab between crossed polarizing sheets with a camera (Nikon Coolpix S200).

\subsection{Air porosity: air volume fraction by CT X-ray imaging}

\subsubsection{General principle}

CT scanning is a non-destructive radiographic approach to examine materials by creating a three-dimensional image of density contrasts. Ice cores were imaged using a third generation Siemens Somatom Volume Access sliding gantry medical CT-Scanner (Siemens SOMATOM Definition AS + 128) at the Institut National de la Recherche Scientifique (INRSETE). The ice cores were stored at $-20^{\circ} \mathrm{C}$ and scanned at room temperature. The scan duration was less than $15 \mathrm{~s}$. Including transport of the ice samples from the storage freezer to the CT instrument was less than $75 \mathrm{~s}$. We therefore assume that no temperature change in the core occurred. Data was acquired in spiral mode with a pitch factor of 0.6 ; the $\mathrm{X}$-ray source was set at $120 \mathrm{kV}$ and $150 \mathrm{mAs}$. These configurations produced 1152 projections for each reconstructed axial slice. The image size is limited by the manufacturer to $512 \times 512$ pixels, so the pixel resolution is defined by the chosen field of view (FOV). The smallest selectable FOV is $50 \times 50 \mathrm{~mm}$ providing a pixel resolution of $0.0977 \mathrm{~mm}$ in the transverse plane. This FOV is too small to contain the whole core in one image; so four reconstructions of each core were produced and concatenated together using Matlab. The Siemens SAFIRE (Sinogram Affirmed Iterative Reconstruction) reconstruction algorithm was used (three iterations). The convolution kernel is $\mathrm{J} 70 \mathrm{~h}$, a medium-sharp filter. The result of the concatenation is an image size of $1024 \times 1024$ pixels with a FOV of $100 \mathrm{~mm} \times 100 \mathrm{~mm}$ and a pixel resolution of $0.097 \mathrm{~mm}(x-y)$ and a slice thickness $(z)$ of $0.6 \mathrm{~mm}$. By scanning a core from top to bottom, a threedimensional "stack" of images was produced by compiling individual transverse slices and longitudinal slices (Fig. 1a) yielding $0.097 \times 0.097 \times 0.6 \mathrm{~mm}\left(0.0056 \mathrm{~mm}^{3}\right)$ voxel volumes within square $(1024 \times 1024$ voxel $)$ images.

Hounsfield (1973) and Knoll (1989) describe the X-ray technique in detail. The Hounsfield Unit (HU) value for each voxel corresponds to linear X-ray attenuation (Duliu, 1999), where higher density and higher atomic numbers result in greater X-ray attenuation. Ice core density was calculated in terms of tomographical intensity (TI) (in Hounsfield units for each voxel):

$\mathrm{TI}=\left(\frac{\mu}{\mu_{\mathrm{w}}}-1\right) \cdot 1000$,

where $\mu$ is the linear absorption coefficient of the bulk core, and $\mu_{\mathrm{w}}$ is the linear absorption coefficient of water. $\mu$ is a function of the radiation energy and the atomic number of the core component crossed by the beam and varies in relation to the density of the material. Resulting im- 


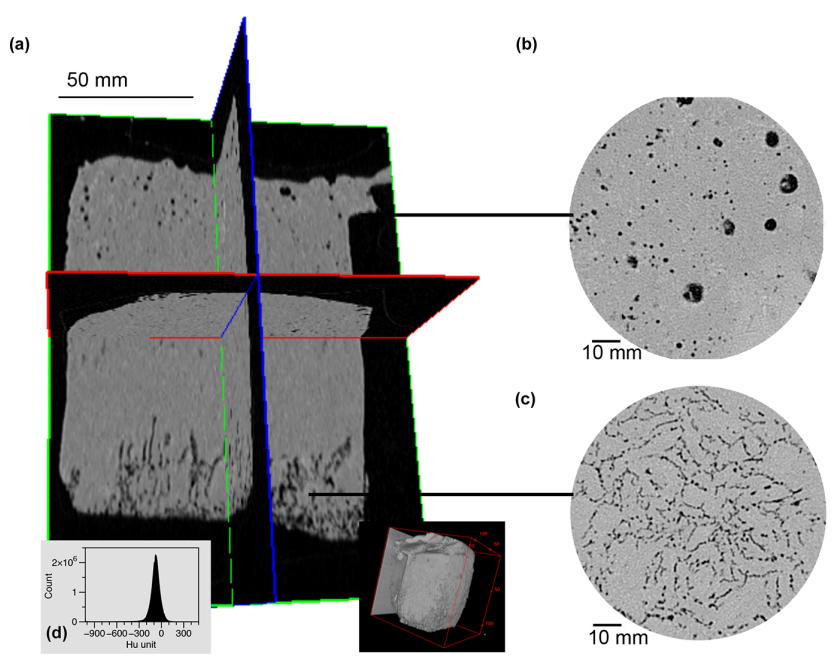

Figure 1. (a) 3-D orthoslice view from raw images of 16 January, consisting of two longitudinal slices and one transversal slice, lighter grey represent the ice matrices and black area represent the air inclusions (i.e., bubbles); (b) top transversal slice at $0.65 \mathrm{~mm}$ depth, every black dot represents an air inclusion (i.e., bubbles); (c) bottom transversal slice at $8 \mathrm{~cm}$ depth, all the black dots show drained brine; (d) histogram of HU-unit (Ct-value) recorded for 186 transversal slices of $0.6 \mathrm{~mm}$ thick for 16 January.

ages are represented in grey scale where darker tones indicate lower density material (e.g., air) (Fig. 1a-c). Density measurements were made relative to freshwater and expressed in TI where water $=0 \mathrm{HU}$ and air $=-1000 \mathrm{HU}$. We observed HU unit from -1024 to $+616,+499$ and +766 on 14, 16 and 25 January, respectively. Positive values are related to brine and to a minor extend precipitated salt (e.g., $60 \mathrm{HU}<\mathrm{TI}<766 \mathrm{HU}$ ) and slightly negative values are related to ice (e.g., $\mathrm{TI}=-84 \mathrm{HU}$; Kawamura, 1988). We estimate the tomographic intensity of pure ice crystals using the mode of the histogram (Fig. 1d, TI $=-74 \mathrm{HU}$ ).

\subsubsection{Processing X-ray images and analysis}

The process of pixel selection to create binary images of air inclusions, thereby defining the air volume fraction (air porosity, $V_{\mathrm{a}}$ ) in the CT imagery, was performed by means of thresholding following the determination of a region of interest (ROI) created by the removal of all pixels not belonging to the core sample (i.e., the sample container, disturbance of the core edges by coring and/or storage, the supporting bench, and surrounding air from each slice). The images were individually examined and ambiguous pixels around the sea ice core sample were also removed. The bottom slices of each imaged ice core were removed due to observed brine drainage resulting from the coring method. A three-dimensional orthoslice view as well as two transversal slices of the ice core sample extracted on 16 January are shown in Fig. 1. The bottom of the ice core from which brine drainage occurred during core extraction can be clearly differentiated from the rest of the core sample unaffected by brine loss on both the orthoslice and transversal slice views (Fig. 1a-c). CTan and ImageJ software were used to quantitatively measure morphometric characteristics of binary (black and white) images.

Determination of the most applicable threshold is therefore of the utmost importance here, as in all image classifications in the multitude of fields that employ the technique. Three approaches are typical for determining an optimal threshold; manual threshold selection based on the human visual system, automated threshold selection based on image data, usually employing the image histogram, and a threshold based on a mixture model approach.

There are many automated segmentation techniques described in the literature. In this study segmentation algorithms representing a selection of established thresholding techniques chosen on the basis that they (i) suited a unimodal histogram (Fig. 1d), and they (ii) showed potential for automated characterization of pore space in geomaterials. Global thresholding specifically was selected on the basis of comparative reviews by Sezgin and Sankur (2004) and Iassonov et al. (2009). Global thresholding may be divided into several subcategories depending on the applied approach. These subcategories include those based on signal entropy considerations (Shannon and Weaver, 1948; Pal and Pal, 1989; Pal, 1996) to separate background and foreground voxels, including EN-Kapur and EN-Yen (Kapur et al., 1985; Yen et al., 1995). There exist global thresholding methods that analyze histogram shape (HS), including HS-Zack and HS-Tsai (Zack et al., 1997; Tsai, 1995). Finally, segmentation may be accomplished by clustering (CL) methods, which separate background (i.e., ice) and foreground voxels (i.e., air) by approximating the histogram with a combination of two or more statistical distributions, including CL-Otsu and CLRidler (Ridler and Calvard, 1978; Otsu, 1979).

Each segmentation method was tested on the three core image sets (633 total image slices), as well as on selected parts of each image set to insure that the algorithm response was stable. The results of each segmentation method were visually evaluated by comparing the raw and segmented images (Fig. 2) and by computing linear profiles of HU value (Fig. 3) through cross-sectional images and examining them visually to determine the efficacy of various thresholds in identifying air inclusions.

Analysis of variance (ANOVA) demonstrated significant $(p<0.005)$ differences between in the thresholds produced by the interrogated segmentation methods. The EN-Yen (max-entropy) algorithm produced a relatively high threshold $(\mathrm{TI}=-200 \mathrm{HU})$, which introduced noise and speckle in the image; $66 \%$ of 1180 total inclusions detected by the ENYen threshold were the size of a single pixel (Fig. 2b, ENYen). The HS-Zack (Zack et al., 1997; Rosin, 2001) method produced a low threshold $(\mathrm{TI}=-569 \mathrm{HU})$ that (i) did not detect small bubbles, and (ii) underestimated the size of bub- 
Table 2. Estimation of the HU value of a pixel containing at least $50 \%$ of air. Assuming the HU value of air, of ice and brine are -1000 , -74 and 200, respectively.

\begin{tabular}{lllllrl}
\hline$V_{\text {air }}=50 \%$ & $V_{\text {air }} \times \mathrm{HU}_{\text {air }}$ & $0 \%<V_{\text {ice }}<50 \%$ & $V_{\text {ice }} \times \mathrm{HU}_{\text {ice }}$ & $0 \%<V_{\text {brine }}<50 \%$ & $V_{\text {brine }} \times \mathrm{HU}_{\text {brine }}$ & HU value* $^{*}$ \\
\hline 0.5 & -500 & 0 & 0 & 0.5 & 100 & -400 \\
0.5 & -500 & 0.1 & -7.4 & 0.4 & 80 & -427.4 \\
0.5 & -500 & 0.2 & -14.8 & 0.3 & 60 & -454.8 \\
0.5 & -500 & 0.3 & -22.2 & 0.2 & 40 & -482.2 \\
0.5 & -500 & 0.4 & -29.6 & 0.1 & 20 & -509.6 \\
0.5 & -500 & 0.5 & -37 & 0 & 0 & -577 \\
\hline
\end{tabular}

$* \mathrm{HU}=\left(V_{\text {air }} \times \mathrm{HU}_{\text {air }}\right)+\left(V_{\text {ice }} \times \mathrm{HU}_{\text {ice }}\right)+\left(V_{\text {brine }} \times \mathrm{HU}_{\text {brine }}\right)$.

(a)

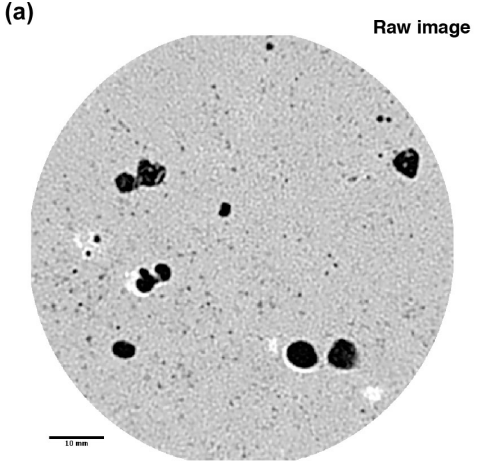

(b)
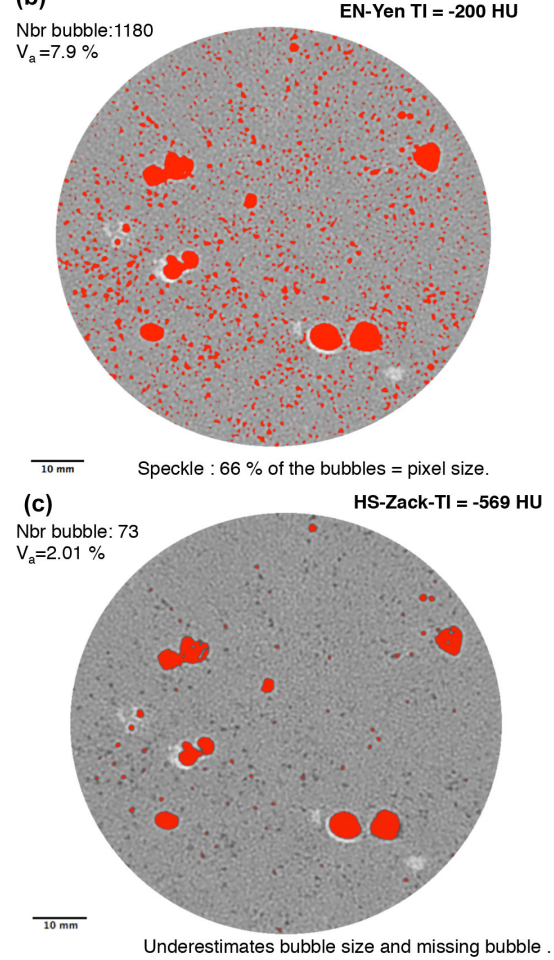

(d)

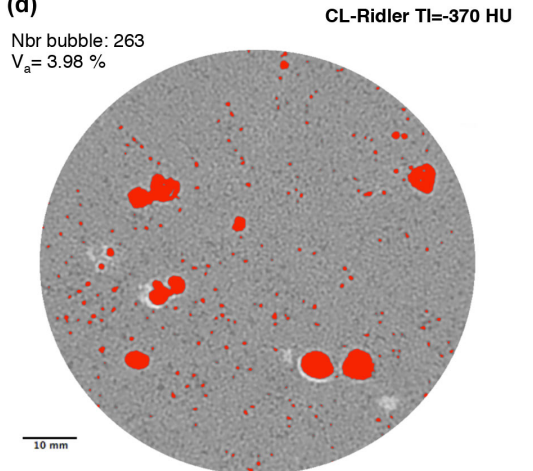

(e)

$\mathrm{Va} \geq \mathbf{5 0} \% \mathrm{Tl}=-\mathbf{4 0 0} \mathrm{HU}$
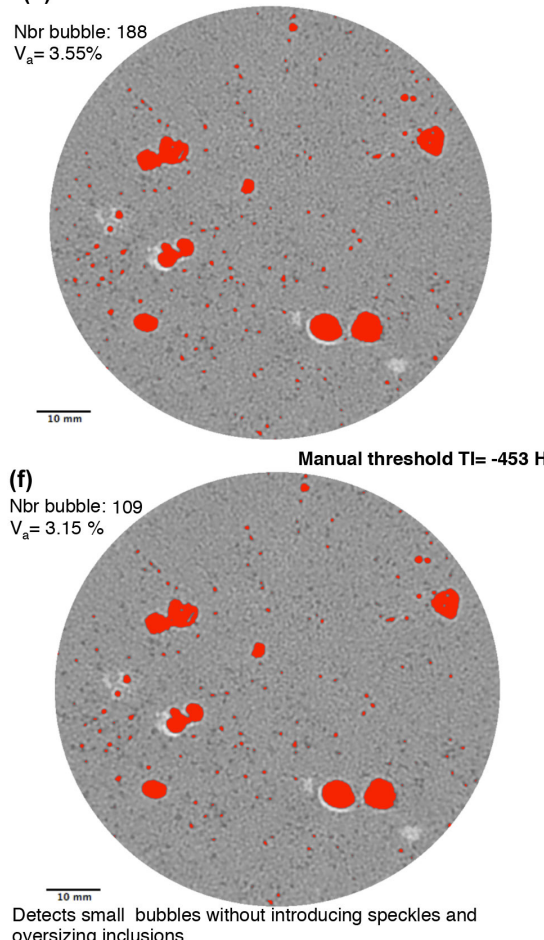

Figure 2. (a) Raw transversal slice where grey pixels represent ice, black pixels represent air, and darker grey pixels are pixel-containing air. (b) and (c) transversal slices showing the air selected pixels in red using a HU value of -200 and of -569 as threshold selected by the EN-Yen (b) and the HS-Zack algorithm (c), respectively. (d), (e) and (f) transversal slices showing the air selected pixels in red using a HU-value of -370 , of -400 and of -453 as threshold selected by (d) CL-Ridler algorithm, (e) by pixels containing a minimum of $50 \%$ of air and (f) by manual thresholding. 
bles detected (Fig. 2c, HS-Zack). The segmentation threshold produced by the CL-Ridler ( $\mathrm{TI}=-370 \mathrm{HU})$, method accurately identified bubbles in all images, including detecting very small bubbles, without introducing speckle in the segmented image (Fig. 2d, CL-Ridler).

Manual segmentation thresholds were defined by inspecting a variety of different bubbles in different slices (e.g., Fig. 3). Figure 3 indicates that visual thresholds were subjective; the pixel scale actually makes visual bubble delineation more ambiguous. Bubble number 2 (Fig. 3) is best delineated by $\mathrm{TI}=-453 \mathrm{HU}$, while bubble number 3 (Fig. 3) is best visually delineated by $\mathrm{TI}=-373 \mathrm{HU}$. In the context of the variety of bubble morphology and the differences in columnar and granular sea ice in the 633 transverse image slices, the visual segmentation threshold was set at $\mathrm{TI}=-453 \mathrm{HU}$.

Finally, the tomographic intensity of "mixed pixels" which appear as varying shades of grey is dependent of the proportion of air $\left(V_{\text {air }}\right)$, ice $\left(V_{\text {ice }}\right)$ an brine $\left(V_{\text {brine }}\right)$ in the pixel and the proportions of the tomographic intensities of those constituents (air $-\mathrm{HU}_{\text {air }}$, ice $-\mathrm{HU}_{\text {ice }}$ and brine $-\mathrm{HU}_{\text {brine }}$ ) in the following mixture model:

$$
\begin{aligned}
& \mathrm{HU}=\left(V_{\text {air }} \times \mathrm{HU}_{\text {air }}\right)+\left(V_{\text {ice }} \times \mathrm{HU}_{\text {ice }}\right)+\left(V_{\text {brine }} \times \mathrm{HU}_{\text {brine }}\right) \\
& 1=V_{\text {air }}+V_{\text {ice }}+V_{\text {brine }} .
\end{aligned}
$$

The TI of pure ice crystals is determined using the mode of the histogram containing all the data from each core $\left(\mathrm{TI}_{\text {pure ice }}=-74 \mathrm{HU}\right)$. Brine $\mathrm{TI}$ values ranged from 60 to 500 depending on brine salinity; we selected the middle point of that range $\left(\mathrm{TI}_{\text {brine }}=200 \mathrm{HU}\right)$. Finally $\mathrm{TI}_{\mathrm{air}}=-1000 \mathrm{HU}$. According to the mixture model (Eq. 3), any pixel $\mathrm{TI} \leq-400 \mathrm{HU}$ contains at least $50 \%$ air and is therefore selected as part of an air inclusion (Fig. 2e, Table 2).

The CL-Ridler ( $\mathrm{TI}=-370 \mathrm{HU}$ ) threshold, as well as the manual threshold $(\mathrm{TI}=-453 \mathrm{HU})$ and the mixture model threshold, which selects pixel containing $50 \%$ air ( $\mathrm{TI}=-400 \mathrm{HU}$ ) were used to compute the air volume fraction for each of the transverse slices in each of the three ice cores imaged. Analysis of variance (ANOVA) demonstrated no significant difference $(p<0.005)$ between the air volume fraction computed using the mixture model threshold and the air volume fraction computed using the visually defined threshold ( $\mathrm{TI}=-453 \mathrm{HU}$ ) or the most applicable automated threshold (CL-Ridler, TI $=-370 \mathrm{HU}$ ). The CL-Ridler and the visual threshold produced mean $V_{\mathrm{a}}$ values that were statistically different $(p<0.005)$.

Hereafter, the air volume fraction is presented as the mean of the air volume fraction results computed using the three selected thresholds. The potential range of the $V_{\mathrm{a}}$ from each of the three methods is represented by the standard deviation of this mean.

Our method endeavors to meet the challenge of CT X-ray image threshold selection in porous materials while lacking knowledge of the optimal segmentation result. Selecting the

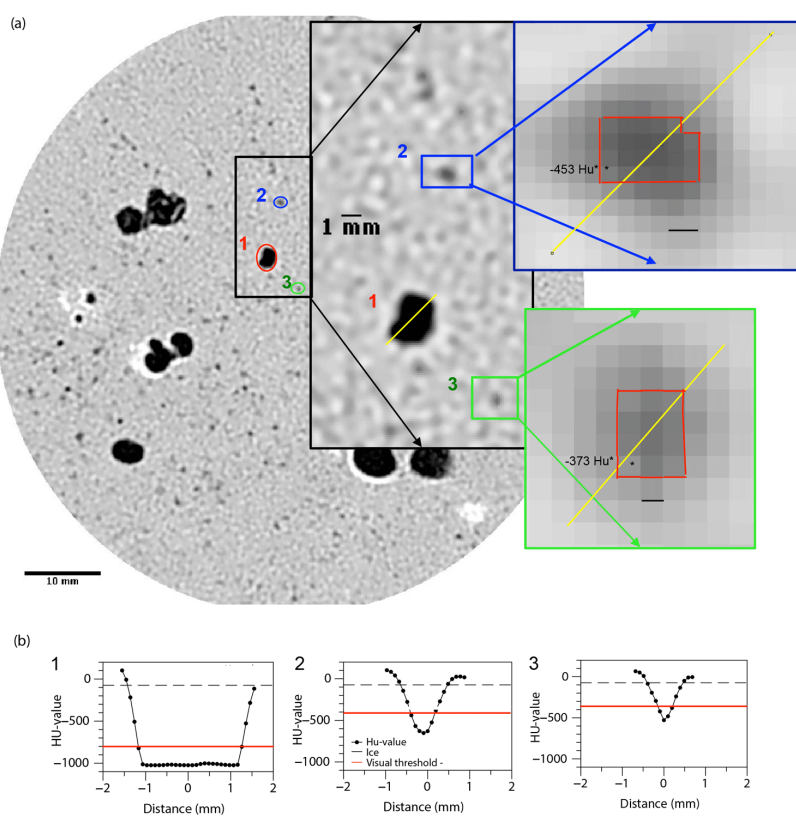

Figure 3. (a) Raw transversal slice where grey pixels represent ice and black pixels represent air; darker grey pixels are pixels containing air and white pixels contain brine. We highlighted three air inclusions: an air inclusion (1) larger than the spatial resolution and two inclusions ( 2 and 3 ) which are smaller than the spatial resolution, their HU value never reached the HU value of air; instead they appeared as mixed pixels and their HU value reflects the proportion of air, ice and brine in the pixel. The red line shows the visual boundary of the bubble where the lowest $\mathrm{HU}$ value observed for pixel $(*)$ is the visual threshold. (b) The distribution of HU value along the transects (yellow lines in a).

most applicable threshold is imperfect because the resolution of the CT-imaged used will almost always be insufficient to resolve every object of interest (in this case air inclusions in sea ice). When the object of interest is smaller than the spatial resolution of the imager, it appears as a mixed pixel, where the voxel TIs is function of the amount of air, of ice and/or brine in the voxel, resulting in voxel TIs different than that of pure ice (or pure air) by some amount. In this way delineation of an object using TI thresholds is complicated by the TIs of adjacent pixels/materials. If an air bubble $(\mathrm{TI}=-1000 \mathrm{HU})$ is adjacent to both ice ( $\mathrm{TI}=-74 \mathrm{HU}$, Fig. 1d) and brine $(\mathrm{TI}=200 \mathrm{HU})$ the pixel(s) those respective boundaries will be roughly -537 on the ice-side and -400 on the brine-side. In granular sea ice (where bubbles are large enough to be resolved by a $\mathrm{Ct}$ scan) mixed pixel concerns mainly the edges of the large and macro bubbles, while in columnar sea ice (where bubbles are small compared to the pixel size) most of the bubbles appeared as mixed pixels as they include both air and background (ice/brines). We are able to compute the $V_{\mathrm{a}}$ in granular layer within with a relative error of $\pm 16 \%$ and in columnar sea ice within with a relative error of $\pm 43 \%$. The morphology of air inclusions is characterized quantitatively 
using their diameters $(\varnothing, \mathrm{mm})$ in the transverse $(x-y)$ plane. While it is ambiguous to report exact diameter from mixed pixel, we classified bubble diameters into three categories at a millimeter scale: micro bubbles $(\varnothing<1 \mathrm{~mm})$, large bubbles $(1 \mathrm{~mm}<\varnothing<5 \mathrm{~mm})$, and macro bubbles $(\varnothing>5 \mathrm{~mm})$.

$V_{\mathrm{a}}$ must be clearly differentiated from the GC-derived bulk ice total gas content (in $\mathrm{mLL}^{-1}$ ice) which refers to the amount of $\mathrm{O}_{2}, \mathrm{~N}_{2}$, and $\mathrm{Ar}$, both (i) in dissolved phase in brine and (ii) in the gas phase in bubbles measured in $5 \mathrm{~cm}$ depth increments. In this work we use the terms "bubbles" and "air inclusions" interchangeably to denote gas phase inclusions in sea ice.

\section{Results}

\subsection{Environmental conditions}

At the Sea-ice Environmental Research Facility (SERF), the ambient air temperature varied between -5 and $-32{ }^{\circ} \mathrm{C}$ through the experiment from 13 to 26 January. The average air temperature for the period was $-22^{\circ} \mathrm{C}$. Three main snowfall events occurred during the experiment. Snowfall on 14 to 15 January covered the sea ice surface with $1 \mathrm{~cm}$ of snow. Snowfall from 19 to 23 January deposited 6-9 cm of snow over the entire pool. On the morning of 23 January, the snow was manually cleared off the ice surface to investigate the insulating effect of snow on the ice temperature and ikaite precipitation (see Rysgaard et al., 2014). Finally, from 24 January to the end of the experiment on 26 January, $8 \mathrm{~cm}$ of snow covered the entire pool. Surface elevation from Lidar data (not shown), indicate that ice surface did not move appreciably in the vertical for the duration of the experiment even as a result of snow removal. Periodically the sea ice froze to the side of the pool resulting in a hydrostatic pressure head in the seawater below, causing episodic percolation of seawater at the freezing point upwards through the sea ice volume resulting in wet snow ice and slush at the sea ice surface on 16 January. A slush layer (up to $3 \mathrm{~cm}$ thick) was also observed at the snow base on 20 January. This episodic hydrostatic pressure head and resultant upward percolation of seawater through the sea ice caused the granular layer of the sea ice volume to thicken over time, likely by the formation of snow ice layers as the slush layer froze. On 14 January, the granular layer was $0.7 \mathrm{~cm}$ frazil ice, on 16 January, the granular layer thickened to $1.7 \mathrm{~cm}$ (consisting of the initial $0.7 \mathrm{~cm}$ of frazil and $1 \mathrm{~cm}$ of snow ice). On 25 January, the granular layer had thickened again to $4 \mathrm{~cm}$ consisting of the initial granular sea ice layer of 14 January, the snow ice layer of 16 January and an additional $2.3 \mathrm{~cm}$-thick snow ice layer (Fig. 4). Below the granular ice layer, the sea ice crystal texture transitioned nearly immediately to columnar ice on all three dates (Fig. 4).

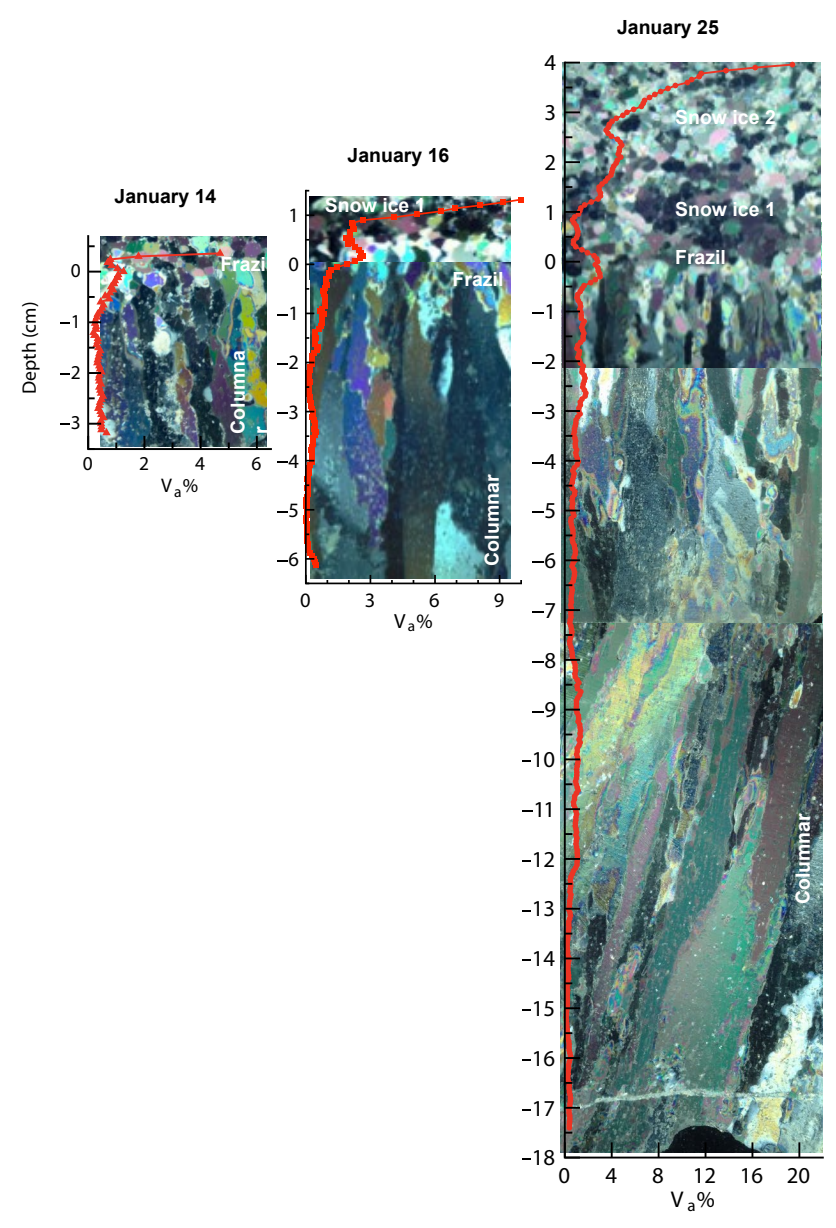

Figure 4. Sea ice microstructural images overlain by the air volume fraction (red curve) for 14, 16 and 25 January. The $x$ scale differs for each date in order to visualize vertical change. The zero depth is fixed at the boundary between granular and columnar ice. Through the studied period ice grew from the bottom increasing the columnar layer, as well as by the top due to additional formation of snow ice.

\subsection{Temperatures, salinity, brine volume fraction and bulk ice density}

Sea ice temperature, bulk salinity, brine volume, and bulk ice density profiles for cores sampled on 14 January $(4 \mathrm{~cm}$ thick), 16 January ( $8 \mathrm{~cm}$ thick) and 25 January ( $22 \mathrm{~cm}$ thick) are shown in Fig. 5 and Table 3.

On 14 January, the bulk salinity profile was approximately linear, and evolved to a more a C-shaped profile on 16 and 25 January as the granular top layer remained saline and the top of the columnar layer desalinated through the experiment (Fig. 5). Calculated brine volume ( $\left.V_{\mathrm{b}}\right)$ profiles were similar in shape to the salinity profiles with minimum $V_{\mathrm{b}}$ occurring in the middle of the columnar ice layer on 16 and 25 January (Fig. 5). According to Golden et al. $(1998,2007)$ the permeability threshold for columnar sea ice of $5 \% V_{b}$ indicates that the whole ice volume on 14 January and near the bottom 
Table 3. Summarizes the main sea ice characteristics and sea ice properties.

\begin{tabular}{|c|c|c|c|c|}
\hline \multicolumn{2}{|c|}{ Data } & 14 January & 16 January & 25 January \\
\hline \multicolumn{2}{|l|}{ Ice thickness $(\mathrm{cm})$} & 4 & 8 & 22 \\
\hline \multicolumn{2}{|l|}{ Temperature $\left({ }^{\circ} \mathrm{C}\right)$} & -4.1 to -1.7 & -8.4 to -1.6 & -5.2 to -2.1 \\
\hline \multicolumn{2}{|l|}{ Salinity } & $11.4-25.8$ & $2.26-10.3$ & $1.3-12.5$ \\
\hline \multicolumn{2}{|c|}{ Brine volume fraction $(\%)\left(V_{\mathrm{b}}\right.$, liquid porosity) } & $11.8-58.6$ & $2.26-20.4$ & $1.3-20.6$ \\
\hline \multicolumn{2}{|l|}{ Bulk ice density $\left(\mathrm{g} \mathrm{cm}^{3}\right)$} & 0.91 & $0.89-0.92$ & $0.84-0.92$ \\
\hline $\begin{array}{l}\text { Air volume fraction } \\
(\%)\left(V_{\mathrm{a}}, \mathrm{CT} \text {-derived }\right. \\
\text { air porosity) }\end{array}$ & $\begin{array}{l}\text { Granular } \\
\text { Columnar impermeable } \\
\text { Columnar permeable }\end{array}$ & $\begin{array}{l}0.69-5.09 \\
\mathrm{n} / \mathrm{a} \\
0.18-1.25^{*}\end{array}$ & $\begin{array}{l}1.8-10 \\
0.13-1.89 \\
0.02-0.87\end{array}$ & $\begin{array}{l}0.69-19.41 \\
0.42-3.01 \\
0.11-0.85\end{array}$ \\
\hline $\begin{array}{l}\text { Air inclusions } \\
\text { diameter }(\mathrm{mm})\end{array}$ & $\begin{array}{l}\text { Granular } \\
\text { Columnar impermeable } \\
\text { Columnar permeable }\end{array}$ & $\begin{array}{l}0.097-4.53 \\
\mathrm{n} / \mathrm{a} \\
0.097-1.12\end{array}$ & $\begin{array}{l}0.097-13.31 \\
0.097-4.86 \\
0.097-1.08\end{array}$ & $\begin{array}{l}0.97-18.2 \\
0.097-4.96 \\
0.097-1.18\end{array}$ \\
\hline $\begin{array}{l}\text { Gas composition (average } \\
\text { mixing ratio) }\end{array}$ & $\begin{array}{l}\mathrm{O}_{2} \% \\
\mathrm{Ar} \% \\
\mathrm{~N}_{2} \%\end{array}$ & $\begin{array}{l}23.7 \\
1.4 \\
74.9\end{array}$ & $\begin{array}{l}29.4 \\
2.2 \\
68.4\end{array}$ & $\begin{array}{l}27.24 \\
1.96 \\
70.8\end{array}$ \\
\hline \multicolumn{2}{|c|}{$\begin{array}{l}\text { Buk ice total gas content }\left(\mathrm{mL} \mathrm{L}^{-1} \text { ice, }\right. \\
\left.\mathrm{O}_{2}+\mathrm{Ar}+\mathrm{N}_{2}\right)\end{array}$} & 1.58 & $2.5-4.7$ & $2-6.5$ \\
\hline \multicolumn{2}{|l|}{ Gas saturation factor $\left(\mathrm{SAT}_{\mathrm{f}}\right)$} & 0.82 & $\begin{array}{l}9.5 \text { (top)- } \\
1.2 \text { (bottom) }\end{array}$ & $\begin{array}{l}16 \text { (top)- } \\
0.9 \text { (bottom) }\end{array}$ \\
\hline
\end{tabular}

* $98 \%$ of the air volume fraction recorded was under $1 \%$

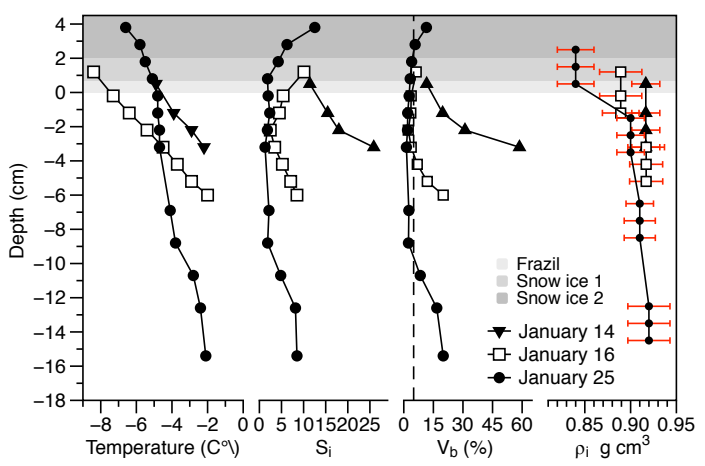

Figure 5. Ice in situ temperature $\left({ }^{\circ} \mathrm{C}\right)$, bulk ice salinity, and brine volume fraction $\left(V_{\mathrm{b}}\right)$ and bulk ice density profiles $\left(\mathrm{g} \mathrm{cm}^{-3}\right)$ on 14 , 16, 25 January. The dotted line at $5 \%$ on the $V_{\mathrm{b}}$ panel refers to the theoretical liquid permeability threshold for columnar sea ice (Golden et al., 1998). Red bars on the density profiles indicate the standard deviation of the mean of density measurements derived from the mass-volume technique.

parts of the columnar ice layer on 16 and 25 January were permeable to liquid.

Bulk ice densities ranged from $0.84 \pm 0.020 \mathrm{~g} \mathrm{~cm}^{-3}$ to $0.92 \pm 0.023 \mathrm{~g} \mathrm{~cm}^{-3}$. The lowest densities were systematically found at the surface of the ice cover (Fig. 5).

\subsection{Bulk ice total gas content}

The total gas content in the sea ice volume increased from its minimum in the bottom permeable columnar layer to its maximum in the top granular layer on 14, 16 and 25 January. The total gas content in the sea ice volume also increased over time (Fig. 6). The total gas content of the permeable columnar bottom of each of the ice cores (and the entire core on 14 January) were close to the concentration at saturation with respect to calculated theoretical atmospheric gas concentrations, leading to saturation factor ranging from 0.8 to 1.2. This will be referred to as "subsaturated" $\left(\mathrm{SAT}_{\mathrm{f}} \leq 1.2\right)$. On the contrary, the total gas content of the impermeable columnar layers and the granular surface layers of the sea ice were largely greater than the concentration at saturation leading to saturation factor ranging form 9.5 to 16 . These will be referred to as supersaturated $\left(\mathrm{SAT}_{\mathrm{f}}>1.2\right)$.

\subsection{Air porosity}

\subsubsection{Air volume fraction $\left(V_{\mathrm{a}}\right)$ derived from CT X-ray image analysis}

For each of the three dates sampled, the air volume fraction increased from the bottom columnar ice layer to the granular surface ice layer and the CT-derived air volume fraction in the sea ice increased overall from 14 to 25 January (Figs. 4 


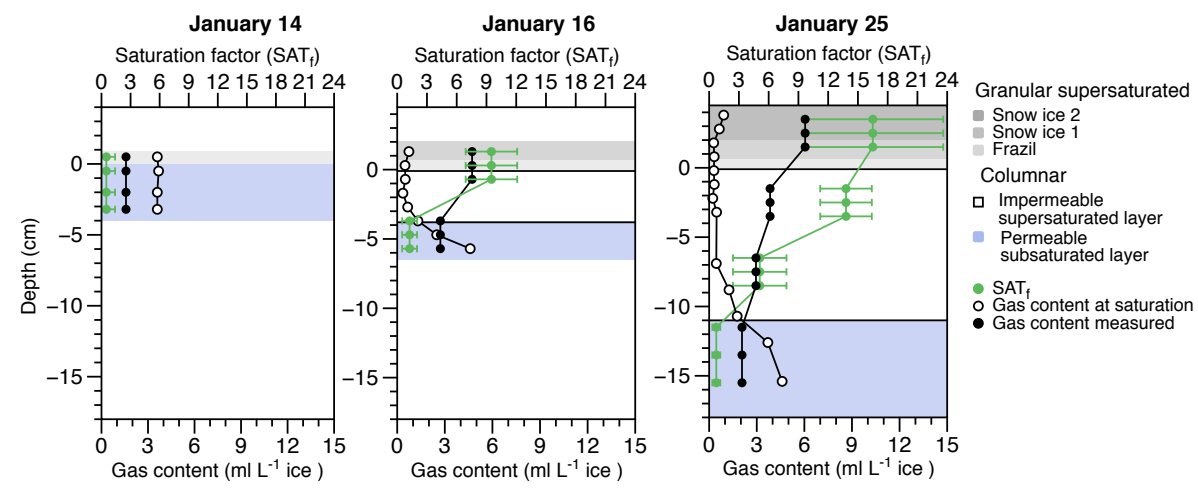

Figure 6. Profiles of the total gas content in bulk sea ice measured by gas chromatography as the sum of $\mathrm{O}_{2}, \mathrm{~N}_{2}$ and $\mathrm{Ar}$ (black symbols) compared (i) to the theoretical bulk ice gas content at atmospheric saturation (white symbols) and (ii) the saturation factor (green symbols). The blue area highlights subsaturated columnar sea ice $\left(\mathrm{SAT}_{\mathrm{f}} \leq 1.2\right)$, the white area highlights the supersaturated columnar sea ice $\left(\mathrm{SAT}_{\mathrm{f}}>1.2\right)$ and the grey area represents successively the supersaturated granular layers (frazil and snow ice layers).

and $7 \mathrm{a}-\mathrm{c})$ in the same way as was shown by the total gas content analysis (Fig. 6).

In columnar ice, we distinguish permeable $\left(V_{\mathrm{b}}>5 \%\right)$ and subsaturated $\left(\mathrm{SAT}_{\mathrm{f}} \leq 1.2\right)$ ice near the bottom (Fig. 7a and b, shaded blue) from the impermeable $\left(V_{\mathrm{b}}<5 \%\right)$ and supersaturated $\left(\mathrm{SAT}_{\mathrm{f}}>1.2\right)$ ice in the middle sea ice layers (Fig. 7a and $\mathrm{b}$, white area). In the permeable subsaturated bottom sea ice, $V_{\mathrm{a}}<1 \%$, for each sampling date (Table 3 ). In the intermediate supersaturated impermeable columnar layer, the air volume fraction was typically under $2 \%$ and increased from 14 to 25 January. At the transition between the impermeable columnar ice and the permeable columnar ice on 16 and 25 January (Fig. 7c, shaded pink), we observed a slight increase in $V_{\mathrm{a}}$.

On all three dates, the maximum air volume fraction occurred in the granular layers nearest the atmosphere interface increasing from the base of the granular layer (Fig. 7c and d). As the granular ice layer thickened by snow ice formation from 0.7 to $4 \mathrm{~cm}, V_{\mathrm{a}}$ in these layers increased (Fig. 7c and d). In the granular layers, the brine volume exceeded $5 \%$ (Fig. 5) and the saturation factor $>9$ on 16 and 25 January (Fig. 6).

\subsubsection{Air inclusion morphology}

The morphology of air inclusions is characterized quantitatively using their diameters $(\varnothing, \mathrm{mm})$ in the transverse $(x$ $y$ ) plane (Fig. 8). We classified CT-derived bubble diameters into three categories: micro bubbles $(\varnothing<1 \mathrm{~mm})$, large bubbles ( $1 \mathrm{~mm}<\varnothing<5 \mathrm{~mm})$, and macro bubbles $(\varnothing<5 \mathrm{~mm})$ (see for e.g., Fig. 8). Bubbles smaller than the pixel size $(0.0097 \mathrm{~mm}$ in the transverse plane) represented less than $10 \%$ of the bubble population in any type of ice except for the impermeable supersaturated columnar layer on 16 January (Fig. 9a). Most of the bubbles had diameters $\leq 1 \mathrm{~mm}$; bubbles of this size were common at every depth in every ice type interrogated by the CT imager (Fig. 9a and b). Due to the non-destructive nature of the CT X-ray method we were able to observe larger bubbles with diameters as large as $18.2 \mathrm{~mm}$ in granular sea ice (Fig. 9b).

For each ice core, the bubble size increased from the bottom columnar layer, to the top granular layer and increased over time in the same way as observed by the total gas content measured using the GC method (Fig. 9b). The bottom permeable subsaturated columnar ice contained almost exclusively micro bubbles on all three dates (Fig. 9a and b). Large bubbles occurred more frequently in the intermediate impermeable supersaturated columnar layer than in the bottom permeable subsaturated columnar layer. Macro bubbles were exclusively found close to the ice-atmosphere interface in the snow ice layer (Fig. 9b).

\section{Discussion}

\subsection{Computed tomography $\mathrm{X}$-ray imaging as a non destructive method to compute the sea ice air volume fraction}

By using computed tomography X-ray imaging with a voxel size of $0.0056 \mathrm{~mm}^{3}$ we provide high-resolution profiles of the vertical distribution of air inclusions in sea ice, from which the sea ice air volume fraction are computed every $0.6 \mathrm{~mm}$. Taking into account the relative errors of $V_{\mathrm{a}} \pm 16 \%$ in granular layer and $V_{\mathrm{a}} \pm 43 \%$ in columnar ice, results of image analysis indicated that the air volume was $<1 \%$ in most of the columnar ice, but systematically reached $5 \%$ in the granular/snow ice top layer where an air volume fraction as high as $19 \%$ was observed.

CT X-ray images (of porous materials in particular) are of such high resolution (in this case voxel $=0.0056 \mathrm{~mm}^{3}$ ), use such large sample volumes and are so quick that traditional methodology can hardly be used to validate the imaged data at the same resolution. Nevertheless, we compared our CT-derived $V_{\mathrm{a}}$ results to air volume fraction computed based 


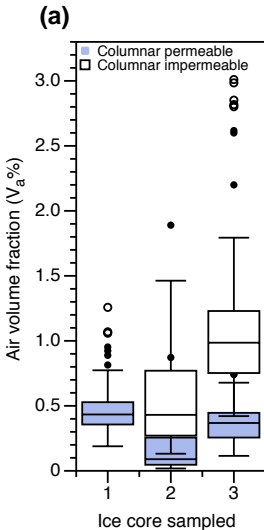

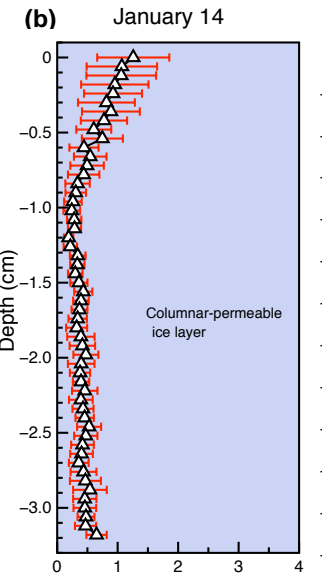

(d)

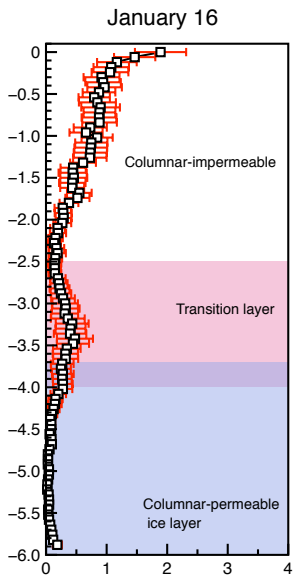

Air volume fraction $\left(\mathrm{V}_{\mathrm{a}} \%\right)$

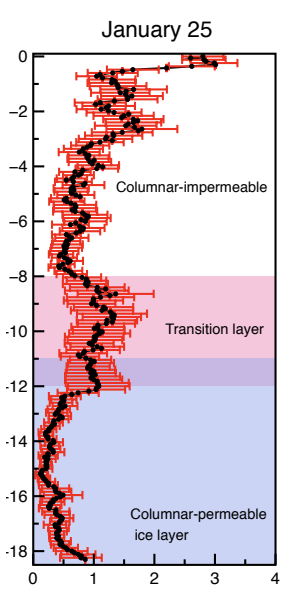

Air volume fraction $\left(\mathrm{V}_{\mathrm{a}} \%\right)$
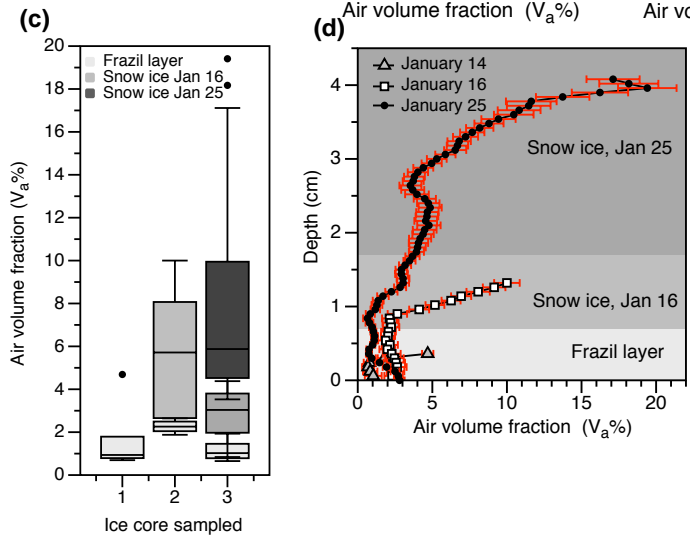

Figure 7. (a) IQR box plot showing the distribution of CT-derived $V_{\mathrm{a}}$ computed for every $0.6 \mathrm{~mm}$ thick slice of each ice core in the columnar impermeable and bottom columnar permeable layers on 14 January (1), 16 January (2) and 25 January (3), respectively. The box is defined by the first and third quartiles of the distribution, the line in the box is the median, the circles represent the outliers (an outlier is any value that lies more than one and a half times the length of the box from either end of the box, $T$ bars). (b) $V_{\text {a }}$ profile in the columnar layers for 14 , 16 and 25 January, respectively. The $y$ scale differs for each date to obtain better visualization of the $V_{\mathrm{a}}$ profile. The errors bars show the potential range of CT-derived $V_{\mathrm{a}}$ in each transverse slice. (c) IQR box plot showing the distribution of CT-derived $V_{\mathrm{a}}$ computed for every $0.6 \mathrm{~mm}$ thick slice of each ice core in granular layers and (d) $V_{\text {a }}$ profile in granular ice for each sampling date.

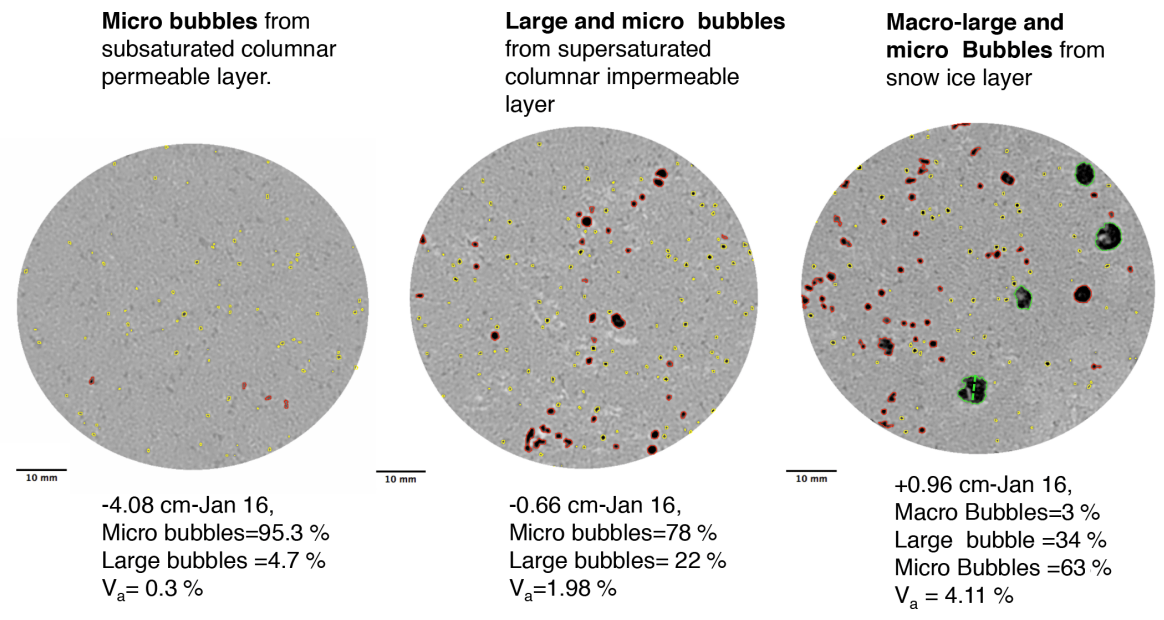

Figure 8. Transversal slice at different depth highlighting the proportion of micro (yellow), large (red) and macro (green) bubbles in each slice (e.g., [Nbr micro/(Nbr micro + NbrLarge + Nbr Macro) $] \times 100)$. 


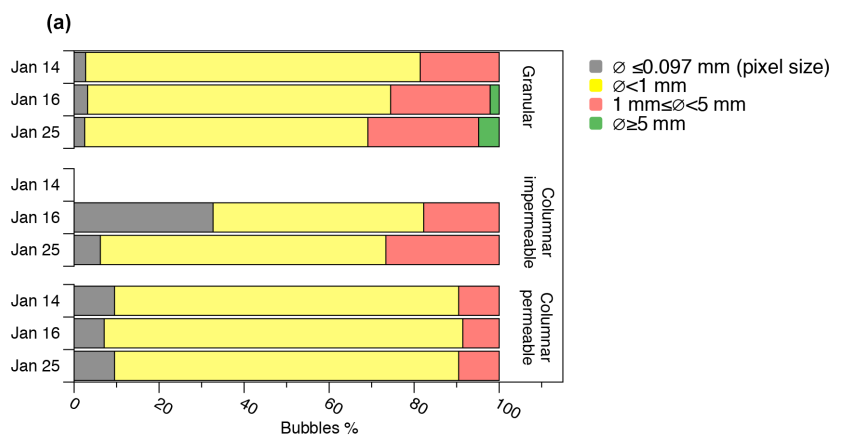

(b)

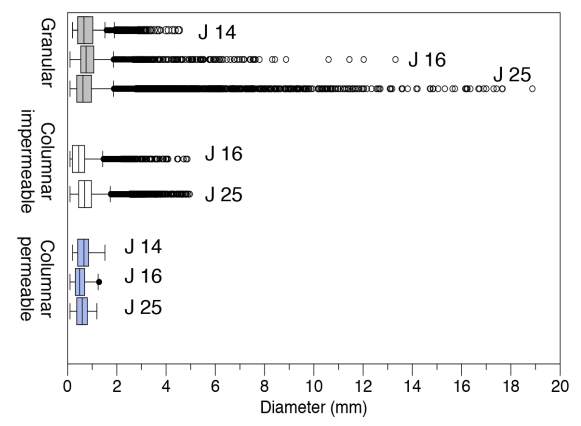

Figure 9. (a) The proportion of micro, large, and macro bubbles for each ice type and sampling date. (b) IQR box plot showing the distribution of the bubble diameters, per ice type and sampling dates. The box is defined by the first and third quartiles of the distribution, the line in the box is the median, the circles represent the outliers (an outlier is any value that lies more than one and a half times the length of the box from either end of the box, $T$ bars).

on density measurements (Cox and Weeks, 1983) (Fig. 10a). The density $(M / V)$ derived air volume profiles were always larger (Fig. 10a) but both methods derive large difference between granular and columnar air porosity and showed similar trends (Fig. 10b). The precision in density-derived $V_{\mathrm{a}}$ is very low $( \pm 163 \%)$, compared with the relative standard deviation from CT- derived volume fraction of $V_{\mathrm{a}} \pm 16 \%$ in granular layer and $V_{\mathrm{a}} \pm 43 \%$ in columnar sea ice. The CT-derived air volume fraction also compared to the bulk ice total gas content ( $\mathrm{mL} \mathrm{L}^{-1}$ ice) data derived from the GC analysis (using $60 \mathrm{~g}$ samples from $5 \mathrm{~cm}$-thick sections) (Fig. 10c). The vertical gradients in the two data sets increased similarly from the ice bottom to the sea ice surface and both the total gas content ( $\mathrm{mL} \mathrm{L}^{-1}$ ice) and the CT-derived air volume fraction increased as the ice thickened over time.

Correlation between CT-derived air volume fraction and the bulk ice gas content ( $\mathrm{mL} \mathrm{L}^{-1}$ ice; Fig. 10c) is not straightforward due in part to methodological constraints. The data compared well in columnar sea ice while in granular layer, we observed large deviations (Fig. 10c). In granular ice, the total gas content was much lower than the CT-derived air volume fraction. CT image voxels are $0.0056 \mathrm{~mm}^{3}$, whereas the bulk ice total gas content was measured on $5 \mathrm{~cm}$ sections. Those $5 \mathrm{~cm}$-thick sections did not always resolve the
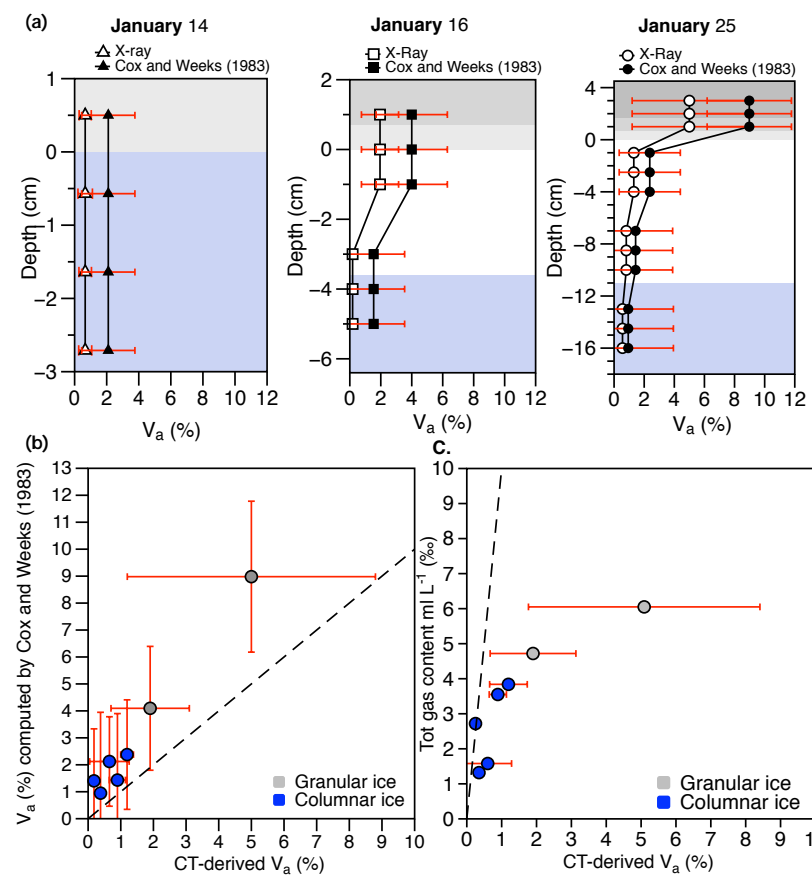

C.

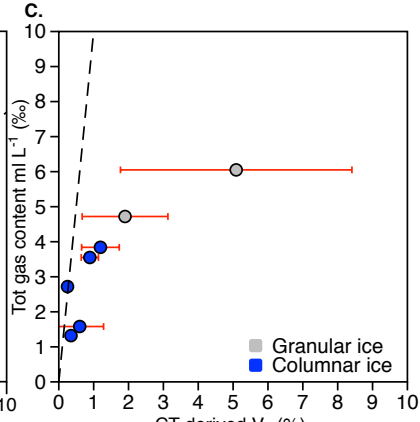

Figure 10. (a) Air volume fraction profiles derived from the Cox and Weeks (1983) equations (filled black symbols) using density measurements, with error bars showing the standard deviation from the mean of the results. These are compared to the CT-derived air volume fraction averaged for $5 \mathrm{~cm}$ section (filled white symbols) which error bars show the standard deviation of the mean along the $5 \mathrm{~cm}$ section. (b) The relationship between CT-derived air volume fraction and the Cox and Weeks (1983) air volume fraction where the dotted line signifies the $1: 1$ relationship. (c) The relationship between CT-derived air volume and the GC-derived bulk ice total gas content measured where the dotted line signifies the $1: 1$ relationship. In (b) and (c) the CT-derived air volume fractions are averaged for $5 \mathrm{~cm}$ section and error bars show the standard deviation of the mean along the $5 \mathrm{~cm}$ section. Where CT-derived air volume fraction spans a large range of values along the section (e.g., granular ice), the standard deviation of CT-derived air volume fraction increases.

changes in ice type. Within the $5 \mathrm{~cm}$ sections, gas might span a large range of concentration as does the air volume fraction in granular sea ice (Fig. 10c, error bar); therefore if thinner sections had been analyzed for the total gas content $\left(\mathrm{mLL}^{-1}\right.$ ice) the values obtained might have been higher in the top part of the ice core, similar to the CT image data. Moreover, the measurement of the total gas content is a destructive sampling process, involving multiple steps in which the gas could potentially leave the ice. During the cutting process, some bubbles are inevitably cut in half, so part of the gas is lost. This is further complicated by the fact that the probability of cutting a large bubble (with high gas content) is greater than for a small bubble with low gas content. Potential gas loss could also happen during the evacuation phase of the measurement of the total gas content (i.e., Sect. 2.3). For 
all these reasons, the total gas content $\left(\mathrm{mLL}^{-1}\right.$ ice) is likely to be particularly underestimated in the granular surface ice due the analytical procedure. The data however agree well in columnar sea ice. The bulk ice total gas content measured by gas chromatography includes both gas dissolved in brine and gas trapped in bubbles, while CT-derived air volume fraction only accounts for gas trapped in bubbles. Then, we expect the total gas content values to be slightly higher than the CTderived air volume fraction due to the dissolved contribution. In reality, the total gas content appears to be slightly lower (Fig. 10c). It suggests that either the CT-derived air volume fraction is slightly overestimated in columnar sea-ice due to the thresholding process or that the total bulk gas is slightly underestimated due to gas loss during the cutting and evacuation phase of the measurement process. Finally, the bulk ice total gas content was measured on different ice cores from those used for the CT measurements, which may have introduced some spatial variability.

The temperature during storage potentially influences our computation. Storing sea ice at $-20^{\circ} \mathrm{C}$ alters the sea ice microstructure and its inclusions (e.g., Cox and Weeks, 1986). Light et al. (2003) proceeded to a cooling sequence ( -2 to $\left.-25^{\circ} \mathrm{C}\right)$ and a warming sequence $\left(-25\right.$ to $\left.-2{ }^{\circ} \mathrm{C}\right)$ on ice thin sections. According to their results cooling sea ice caused inclusions to shrink in size including the disappearance of the smallest air inclusions, while warming increased the size of existing air inclusions without forming new bubbles. Considering that the smallest bubbles could have disappeared and some have shrunk in size, our computed air volume fraction should be considered as a minimum estimate of the true air volume fraction. In the absence of a method that preserves the natural temperature gradient within sea ice immediately and without change upon extraction, ex situ analysis of sea ice samples after storage at low temperatures is an established protocol.

Although microstructural analysis of sea ice may produce reliable morphological results for air inclusions, thin sections only represent a small subsample of the ice core, are time consuming, can be operator-dependent, and the area and thickness of a thin section limit these studies to the measurement of intact bubbles within a thin section. Densityderived air volume fraction results from the mass-volume technique generally have large errors and very low vertical resolution because they require large core subsample volumes (e.g., $\left.5 \mathrm{~cm}^{3}\right)$. On the contrary, CT X-ray imaging clearly distinguishes between air inclusions and the ice matrix providing high-resolution sub-millimeter profiles of the air volume vertical distribution with a better precision linked almost entirely to the segmentation process and the resolution of the scanner. X-ray tomography allows: (1) fast visualization of the air inclusions, especially when compared to transmitted images; (2) the ability to increase the size of the data set compared to thin section microstructural analysis by imaging the whole core. Future work should involve micro CT - X-ray with a voxel resolution of 1 order of magnitude

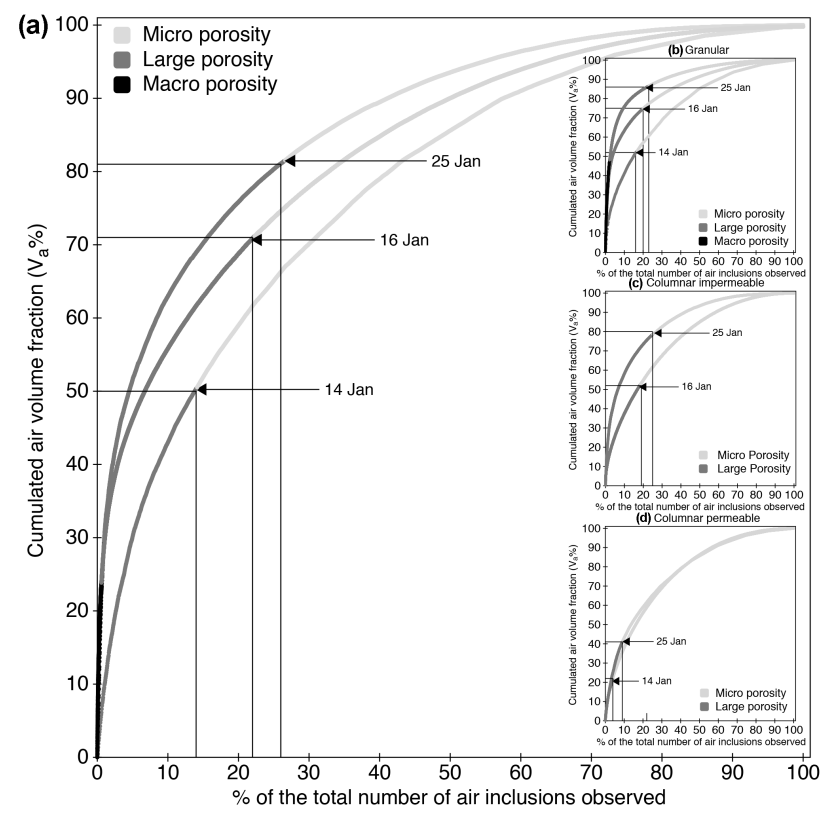

Figure 11. The cumulated contribution of the macro, large and micro bubbles to the cumulated relative air volume fraction for the whole ice core (a), and in granular (b), columnar impermeable (c) and columnar permeable ice (d). It shows that, a smaller number of large bubbles (e.g., Large on 25 January) produced most of the air volume fraction (i.e porosity), and this is true for both the whole ice core (a) and for each type of ice (b, $\mathbf{c}, \mathbf{d})$.

higher than the present one in order to detect the small bubbles in columnar sea ice as well as research on the effect of temperature changes on sea ice gas inclusions.

\subsection{Size of the air inclusion (i.e., bubbles): micro, large and macro air porosity}

While large and macro bubbles account for less than 17 , 22 and $27 \%$ of the bubble population observed for $14 \%$, 16 and 25 January respectively (Fig. 11a), the large and macro bubbles contribute systematically to more than $50 \%$ of the total air volume fraction produced (Fig. 11a). Even in bottom columnar ice where large bubbles represent only $10 \%$ of the bubble population (Fig. 11d), they contributed to 40 and $22 \%$ of the air porosity of bottom columnar ice on January 14 and 25 respectively (Fig. 11d). For each ice type - granular (Fig. 11b), columnar impermeable (Fig. 11c) and columnar permeable (Fig. 11d) - it is clear that the largest bubbles contribute most to the air porosity (Fig. 11, Table 4), which is not surprising as the latter depends on air bubble size cubed. However air porosity in the permeable columnar layer where the proportion of large bubbles decreased (Fig. 12) seems largely to be controlled by the amount of bubbles (i.e., bubble density number). Increasing the number of bubbles produces also a linear increase in the air volume fraction (Fig. 12) in columnar ice. 
Table 4. Classification and properties of the air inclusions. The "abundance" is the proportion of micro, large, and macro bubbles on the total number of air inclusions observed $(100 \%$ is the total number of inclusions in the three data sets (14 Jan $+16 \mathrm{Jan}+25 \mathrm{Jan})$ ). The "contribution" is the percentile of the porosity produced by the micro, large and macro inclusions (100\% is the total of air volume fraction observed in the three data sets (14 Jan +16 Jan +25 Jan)).

\begin{tabular}{lrcl}
\hline $\begin{array}{l}\text { Air } \\
\text { inclusion } \\
\text { classification }\end{array}$ & $\begin{array}{r}\text { Abundance } \\
\text { (\% of the } \\
\text { total } \begin{array}{r}\text { Nbr of air } \\
\text { inclusions } \\
\text { observed) }\end{array}\end{array}$ & $\begin{array}{r}\text { Contribution } \\
\text { (\% of the air } \\
\text { volume fraction } \\
\text { produced by the } \\
\text { air inclusion) }\end{array}$ & \\
\hline Micro & $78 \%$ & $29 \%$ & $\begin{array}{l}\text { Columnar and Granular } \\
\text { Columnar and Granular } \\
\text { Large }\end{array}$ \\
Macro & $20.7 \%$ & $47 \%$ & $\begin{array}{l}\left.\text { (depends most likely of } V_{\mathrm{b}}\right) \\
\text { Granular/snow ice }\end{array}$ \\
\hline
\end{tabular}

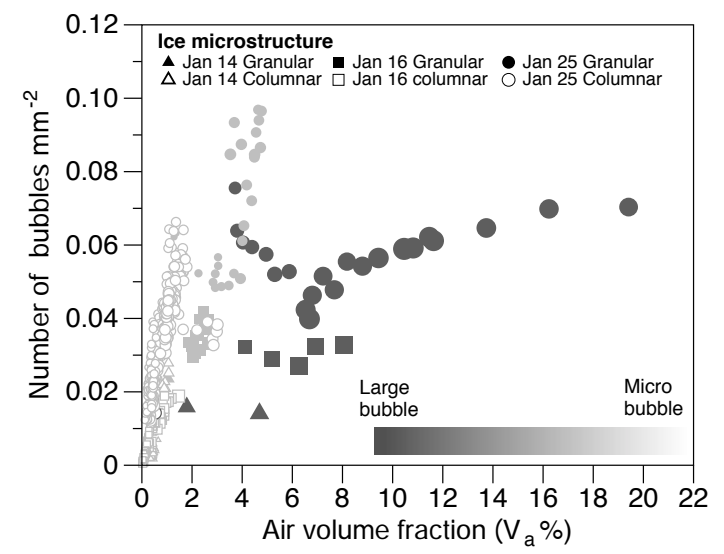

Figure 12. The relationship between bubble density: number of bubbles per $\mathrm{mm}^{-2}$ (slice area) and air volume fraction per slice as a function of both bubble size class and ice type (granular and columnar crystal texture).

For the air volume fraction to increase above $3 \%$ (e.g., Fig. 12 in the granular layer), the presence of large and macro bubbles are required (Fig. 12).

Large bubbles were more prevalent when brine volume increased (Fig. 13a, red and grey circles). Light et al. (2003) observed that bubbles were contained within brine and concluded that bubble size was limited by the size of the brine inclusion in which they resided. In several slices, we observed lighter pixels around air inclusions indicating these bubbles likely formed in a brine pocket. The CT-scanner used here cannot unambiguously identify these pixels as brine inclusions. To visualize both air and brine inclusions in the same images, finer resolution with respect to sample density and finer spatial resolution are required. For example, Obbard et al. (2009) showed that micro-X-ray-computed tomography with a higher voxel resolution of 1 order of magnitude is suitable for visualization of brine and air inclusions.

\subsection{Mechanism for gas incorporation and bubbles development}

In our sea ice samples, the top granular layers are supersaturated, have large air volume fractions $\left(V_{\mathrm{a}}>5 \%\right)$ and contain macro bubbles. The impermeable columnar layers are supersaturated as well but contain lower air volume fractions $\left(V_{\mathrm{a}}<2 \%\right)$ and contain micro to large bubbles. The bottom permeable columnar layers are subsaturated, contain air volume fractions $<1 \%$, and contain almost exclusively micro bubbles (see summary Table 5).

In the multiphase sea ice system, the ratio between dissolved gas and bubbles should depend on the bulk ice gas saturation state. In a closed system, when bubble nucleation is exclusively solubility driven, we expect the air volume fraction to be a function of the saturation factor, which would lead to subsaturated sea ice being bubble-free, and high air volume fractions in supersaturated sea ice. However, the observed relationship between air volume fraction and saturation factor is not straightforward (Fig. 13b) and highlights difference between the type of ice (i) bottom permeable columnar ice, (ii) intermediate impermeable columnar ice and (iii) top granular ice.

\subsubsection{Bottom permeable columnar ice}

Within the permeable subsaturated columnar layer near the sea ice bottom, the air volume fraction is lower than $1 \%$ due to the subsaturated state of the ice, and independent of the brine volume fraction (Fig. 13a and b, blue circles). As long as the brine is able to exchange with the underlying seawater (i.e., when the $V_{\mathrm{b}}$ is $>5 \%$ after Golden et al., 1998), the saturation factor remains low and gas species remain dissolved in the brine and can be rejected to the underlying water by convection from the permeable columnar layer. This limits bubble formation, and hence the air volume fraction was $<1 \%$ (Fig. 13a and b, blue circles). Although the air volume fraction is low in these layers, it is somewhat surprising that the air volume fraction is $>0$; in theory, bubble nucleation oc- 
Table 5. Physical characteristics of the various ice types. Where the brine volume exceeds the permeability threshold for columnar ice of $5 \%$ $\mathrm{V}_{\mathrm{b}}$ (Golden et al., 1998, 2007), the ice layer is referred to as permeable.

\begin{tabular}{|c|c|c|c|c|}
\hline \multicolumn{2}{|l|}{ Data } & 14 January & 16 January & 25 January \\
\hline \multirow{5}{*}{ Granular } & \multirow{2}{*}{ Permeability } & Permeable & Permeable & Permeable \\
\hline & & $V_{\mathrm{b}}=11 \%$ & $V_{\mathrm{b}}=6.2 \%$ & $3.9 \%<V_{\mathrm{b}}<12 \%$ \\
\hline & Saturation & & $\begin{array}{l}\text { Supersaturated } \\
\mathrm{SAT}_{\mathrm{f}}=9.5\end{array}$ & $\begin{array}{l}\text { Supersaturated } \\
\mathrm{SAT}_{\mathrm{f}}=16\end{array}$ \\
\hline & $\begin{array}{l}\text { Air volume } \\
\text { fraction }\end{array}$ & $0.74-5.09 \%$ & $1.8-10 \%$ & $0.69-19.41 \%$ \\
\hline & Bubble class & $\begin{array}{l}\text { Micro and } \\
\text { large }\end{array}$ & $\begin{array}{l}\text { Micro, large } \\
\text { and macro }\end{array}$ & $\begin{array}{l}\text { Micro, large } \\
\text { and macro }\end{array}$ \\
\hline \multirow{4}{*}{ Intermediate columnar } & \multirow{4}{*}{$\begin{array}{l}\text { Permeability } \\
\text { Saturation } \\
\text { Air volume } \\
\text { fraction } \\
\text { Bubble class }\end{array}$} & $\mathrm{n} / \mathrm{a}$ & Impermeable & Impermeable \\
\hline & & $\mathrm{n} / \mathrm{a}$ & Supersaturated & Supersaturated \\
\hline & & $\mathrm{n} / \mathrm{a}$ & $V_{\mathrm{a}}<2 \%$ & $V_{\mathrm{a}}<2 \%$ \\
\hline & & $\mathrm{n} / \mathrm{a}$ & Micro and large & Micro and large \\
\hline \multirow{5}{*}{ Bottom columnar } & Permeability & Permeable & Permeable & Permeable \\
\hline & \multirow[t]{2}{*}{ Saturation } & Subsaturated & Subsaturated & Subsaturated \\
\hline & & $\mathrm{SAT}_{\mathrm{f}} \leq 1.2$ & $\mathrm{SAT}_{\mathrm{f}} \leq 1.2$ & $\mathrm{SAT}_{\mathrm{f}} \leq 1.2$ \\
\hline & \multirow{2}{*}{$\begin{array}{l}\text { Air volume } \\
\text { fraction } \\
\text { Bubble class }\end{array}$} & $V_{\mathrm{a}}<1 \%$ & $V_{\mathrm{a}}<1 \%$ & $V_{\mathrm{a}}<1 \%$ \\
\hline & & $90 \%$ Micro & $90 \%$ Micro & $90 \%$ Micro \\
\hline
\end{tabular}

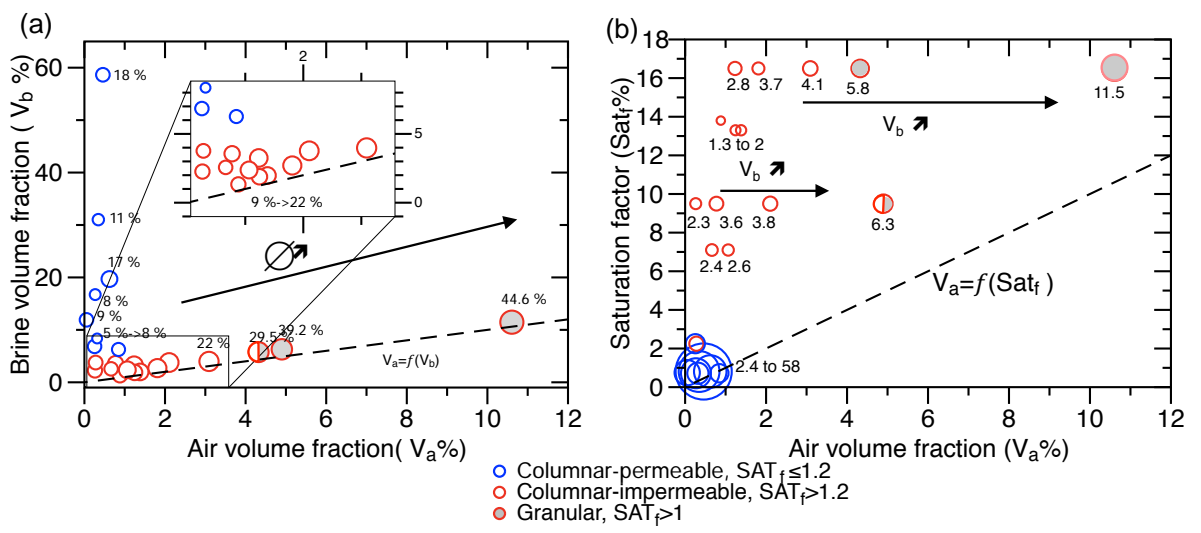

Figure 13. (a) Relationship between brine volume fraction and air volume fraction as a function of the bubble size (where the size of each marker circle is proportional to the percentage of bubbles with diameters $>1 \mathrm{~mm}$, written as \% value next to some of circles). (b) Relationship between the air volume fraction and the saturation factor as a function of the brine volume fraction. The size of each circle denotes the brine volume fraction (\%, written next to some of the circles). In each panel, the bottom columnar permeable subsaturated ice $\left(\mathrm{SAT}_{\mathrm{f}} \leq 1.2, \mathrm{blue}_{\mathrm{fir}}\right.$ cles) is differentiated from the columnar impermeable supersaturated ice $\left(\mathrm{SAT}_{\mathrm{f}}>1.2\right.$, red circles), and from the top granular supersaturated ice $\left(\mathrm{SAT}_{\mathrm{f}}>1.2\right.$, grey circles). In each panel, the dotted line signifies the $1: 1$ relationship.

curs when $\mathrm{SAT}_{\mathrm{f}}>1$, so these subsaturated layers should be bubble-free, though bubble nucleation from saturated gas solutions has been observed at much lower saturations than theoretically expected (Lubetkin, 2003). On 14 January, $75 \%$ of the bubbles observed were located in subsaturated permeable bottom layer of columnar sea ice. On 16 and 25 January, 11 and $13 \%$ (respectively) of the air inclusions observed were situated in subsaturated permeable sea ice. Bubble nucleation processes are favored where (i) there are geometrical imperfections (Wilt, 1986); (ii) at "active sites" on a heterogeneous surface that can be chemically, structurally, or geometrically inhomogeneous (Deutscher and Fletcher, 1990; Kozisek et al., 2000); and (iii) by heterogeneous supersaturation away from thermodynamic equilibrium ( $\mathrm{Li}$ and Yortsos 1994), conditions which are all met in sea ice. The contact of the three phases (solid ice, liquid brine, air bubble and precipitated salt) in brine inclusions produced a highly heterogeneous surface, which is both chemically and struc- 
Table 6. Main parameters influencing the air volume fraction. The "abundance" is the proportion of the inclusions concerned by the processes on the total of inclusion observed $(100 \%$ is the total of inclusions observed in the three data sets (14 Jan +16 Jan +25 Jan)). The "contribution" is the percentile of the porosity produced by the inclusions formed by convection driven, solubility driven and snow ice formation processes, respectively ( $100 \%$ is the total of air volume fraction observed in the three data sets (14 Jan $+16 \mathrm{Jan}+25 \mathrm{Jan})$ ).

\begin{tabular}{llccll}
\hline $\begin{array}{l}\text { Nucleation } \\
\text { processes }\end{array}$ & $\begin{array}{l}\text { Limitation } \\
\text { factor }\end{array}$ & $\begin{array}{c}\text { Abundance } \\
\text { (\% of the } \\
\text { total Nbr of } \\
\text { air inclusions } \\
\text { observed })\end{array}$ & $\begin{array}{c}\text { Contribution } \\
\text { (\% of porosity } \\
\text { produced by the } \\
\text { inclusions })\end{array}$ & $\begin{array}{l}\text { Type of air } \\
\text { inclusions } \\
\text { produced }\end{array}$ & Location \\
\hline $\begin{array}{l}\text { Convection } \\
\text { driven }\end{array}$ & $\begin{array}{l}\text { Saturation } \\
\text { level }\end{array}$ & $14 \%$ & $9 \%$ & $\begin{array}{l}\text { Most likely } \\
\text { micro }\end{array}$ & $\begin{array}{l}\text { Subsaturated } \\
\text { columnar }\end{array}$ \\
\hline $\begin{array}{l}\text { Solubility } \\
\text { driven }\end{array}$ & $\begin{array}{l}\text { Brine volume } \\
\text { fraction }\end{array}$ & $60 \%$ & $44 \%$ & $\begin{array}{l}\text { Micro to } \\
\text { large }\end{array}$ & $\begin{array}{l}\text { Supersaturated } \\
\text { columnar }\end{array}$ \\
\hline $\begin{array}{l}\text { Snow ice } \\
\text { formation }\end{array}$ & $26 \%$ & $47 \%$ & $\begin{array}{l}\text { Micro } \\
\text { large } \\
\text { macro }\end{array}$ & $\begin{array}{l}\text { Granular/ } \\
\text { snow ice }\end{array}$ \\
\hline
\end{tabular}

turally inhomogeneous. Moreover, full-depth convection on 14 January and convection confined to the permeable subsaturated bottom columnar layer of sea ice $\left(V_{\mathrm{b}} \approx 20 \%\right)$ on 16 and 25 January likely produced local fluctuations in the amount of gas-saturated liquid, creating the possibility of local or episodic supersaturation that may have produced bubbles as has been observed by Zhou et al. (2013). Convectiondriven nucleation processes likely produced micro bubbles in columnar permeable sea ice, which contributed to $9 \%$ of the total air volume fraction observed (Table 6). Therefore, brine drainage is only effective for the transport of dissolved gases to the underlying seawater. The rejection of dissolved gas contributes to maintain gas concentrations close to the equilibrium. Nucleation processes driven by the convective exchange in the bottom layer however limited by the saturation state increase the total gas content $\left(\mathrm{mL} \mathrm{L}^{-1}\right.$ ice) of sea ice by ensuring that gas trapped in bubbles remains within the sea ice and is not rejected to the underlying water (Tison et al., 2002).

On 16 and 25 January, we observed a slight increase of air volume fraction at the transition between the subsaturated permeable columnar sea ice and the supersaturated impermeable columnar sea ice at two-thirds of the total sea ice thickness (isotherm -4.1 and $-3.8^{\circ} \mathrm{C}$, respectively) (Fig. 7b, shaded pink area). This imparts that bubbles created by convection-driven nucleation in the permeable bottom layer, naturally accumulate at the brine permeability transition as result of their buoyancy. Our work indicates that brine will start to supersaturate $\left(\mathrm{SAT}_{\mathrm{f}}=2.7\right.$ to 5$)$ under cooling (isotherm -4.1 and $-3.8^{\circ} \mathrm{C}$, respectively) when the sea ice begins to become vertically impermeable to liquid, leading to solubility-driven nucleation. During ice growth period, we could expect an increase of air volume fraction above the permeable bottom layer forming a layer of entrapped bubbles. As long as the intermediate columnar ice stays impermeable (i.e., absence of warming), this bubbly transition layer will grow thicker as the ice thickens.

\subsubsection{Intermediate impermeable columnar sea ice}

Within the supersaturated impermeable columnar layer, bubble nucleation is solubility driven and we expect the air volume fraction to be a function of the saturation factor. Within the supersaturated impermeable columnar layer, the air volume fraction becomes increasingly a function of the saturation factor as the brine volume increases (Fig. 13b, red circles). At low brine volumes, the air volume fraction is low regardless of the saturation factor, as indicated by the accumulation of red circles in the top left corner of Fig. 13b. As brine volume increases in the impermeable supersaturated intermediate columnar layer, both air volume fraction and bubble size increase (Fig. 13a and b). At a given $\mathrm{SAT}_{\mathrm{f}}$, there are more gas molecules available to go into the gas phase when brine volume increases, thereby increasing the air volume fraction and the size of existing bubbles. We therefore suggest that bubble nucleation is a function of the saturation factor as well as the brine volume. Solubility-driven nucleation produced micro bubbles and large bubbles depending on the brine volume in this layer; this contributed $44 \%$ of the total observed air volume fraction (Table 6).

\subsubsection{Granular sea ice}

We observed an increase of air volume fraction nearest the ice-atmosphere interface and generally within the ice surface granular ice layer (Fig. 7c and d). This granular surface layer had the highest gas content, the highest saturation factor, the highest air volume fraction $\left(5 \%<V_{\mathrm{a}}<19.4 \%\right)$ and contained bubbles with diameters as large as $4.5,13$, and $18 \mathrm{~mm}$ on 14, 16 and 25 January, respectively (Table 5 and Fig. 9b). The increase of air volume fraction and the total gas 

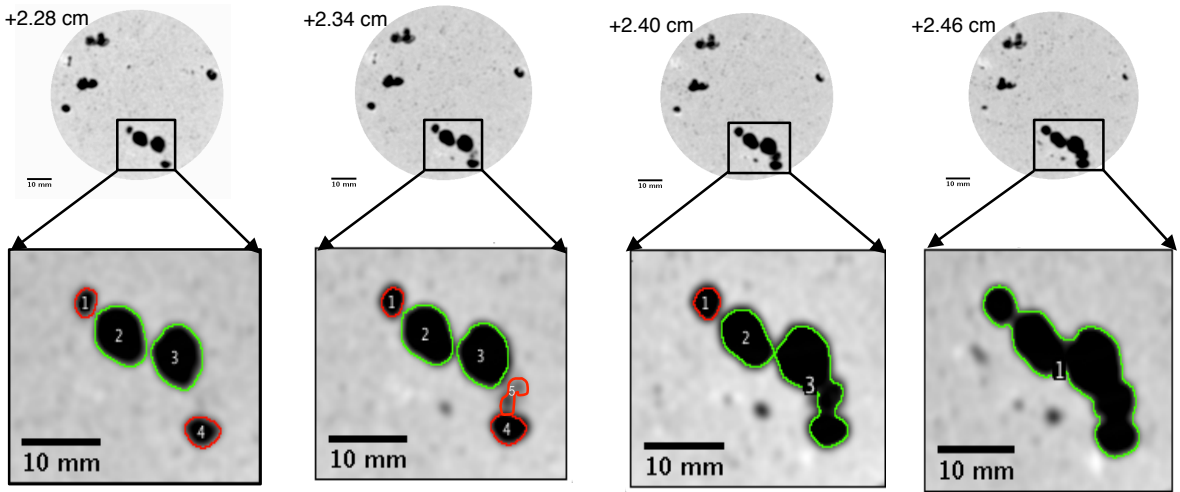

Figure 14. Four successive slices in the snow ice layer on 25 January from +2.28 to $+2.46 \mathrm{~cm}$ below the surface. At $2.28 \mathrm{~cm}$, four individual bottom end of bubbles exist where at $2.46 \mathrm{~cm}$, the top end of each bubbles are joined and formed a single bubble.

content (largely underestimated) in the surface granular layer can be explained by a combination of several processes.

The formation of frazil ice is known to contain more gas than columnar ice because it traps gas directly from the atmosphere (Tsurikov, 1979; Cole et al., 2004; Zhou et al., 2013); this explains the increase of air volume fraction in the frazil ice formed on 14 January. Snow-ice formation observed thereafter on 16 and 25 January trapped gas initially contained within the snow. Moreover, rapid freezing of slush forces gas out of solution, building up the air volume fraction nearest the ice-atmosphere interface.

Macro bubbles are exclusively found in granular layer. They seem to be the result of aggregation of discrete bubbles, like an aggregation of soap bubbles. A succession of $0.6 \mathrm{~mm}$ thick transversal slices from $+2.28 \mathrm{~cm}$ depth from $25 \mathrm{Jan}$ uary is shown in Fig. 14. In the first slice at $+2.28 \mathrm{~cm}$ depth (Fig. 14, far left panel) four individual bubble bases are identifiable from which a single top bubble is formed at $+2.46 \mathrm{~cm}$ depth (Fig. 14, far right panel). The rapid freezing of slush in porous snow could potentially produce bubble aggregation. Granular sea ice and snow ice accounted for $26 \%$ of the bubble population observed, and snow ice formation accounted for $47 \%$ of the total porosity recorded indicating that physical processes associated with snow on new and young sea ice play an important role in the gas dynamics of new and young sea ice.

\subsection{The fate of gas vs. the fate of salt}

Bulk salinity and bulk ice total gas content ( $\mathrm{mLL}^{-1}$ ice) of sea ice is lower than in the seawater from which it formed, because gases in seawater are preferentially expelled from growing ice, along with salts (Cox and Weeks, 1983, 1988; Killawee et al., 1998; Tison et al., 2002; Loose et al., 2009, 2011). The range of total gas content values for our samples was 1.6 to $6.5 \mathrm{mLL}^{-1}$, which is in the lower end of ranges reported by Matsuo and Miyake (1966), Tison et al. (2002) and Crabeck et al. (2014b). Zhou et al. (2013) suggested that gas transport through sea ice occurs via processes diverging from those controlling the transport of salt. Since we do not observe similar profiles of these two parameters over time, this also suggests that the same processes do not regulate bulk ice salinity and bulk ice gas content. Rapid desalinization occurred between 14 January and 16 January, and the bulk salinity profile evolved towards a $\mathrm{C}$-shaped profile over time (Fig. 5). In contrast, we observed a linear increase of gas content $\left(\mathrm{mLL}^{-1}\right)$ (Fig. 6) and air volume fraction (Fig. 7) from the base to the sea ice surface and within sea ice as it thickened over time. The transport of gases through sea ice is different from that of the solutes because gases may be present in the form of bubbles, on top of being dissolved in the brine. Our results indicate that a great deal of the air volume fraction of sea ice exists in bubbles and not in the dissolved phase in brine, suggesting that desalination processes have a limited effect on sea ice gas content. Salts dissolved in brine can diffuse and/or be rejected in the underlying seawater during brine convection events, while bubbles are trapped in the ice matrix and can only migrate upward by buoyancy.

The presence of large bubbles and air volume fraction $>5 \%$ in the top of the ice cover should potentially mediate gas fluxes over sea ice. Partitioning between gaseous phase and dissolved phase is of paramount importance for gas transport in sea ice, as it control the direction of transport - upward vs. downward as well as the magnitude. If the gases are in the dissolved phase, they will be mainly transported downwards with the brines, like the other solutes. Few exceptions are the gas diffusion within the brines network that transport gases both ways in function of the concentration gradient (Crabeck et al., 2014a), and upward brine expulsion at the ice-air atmosphere. If the gases are in the gas phase (i.e., bubbles), they are only transported upward due to bubbles' buoyancy. Kotovich et al. (2015) observed that air-ice gas transfer coefficients for $\mathrm{CO}_{2}$ in young permeable artificial sea ice is 5 times larger during ice growth compared to ice decay. They suggest that this difference is due to the formation and transport of bubbles during ice growth. This pro- 
cess appears to provide a very efficient pathway to transport gases within and out of the ice. Indeed, 1-D modeling suggests that bubbles migrating upward out of the ice contribute to $80 \%$ of the $\mathrm{CO}_{2}$ fluxes from sea ice to the atmosphere during ice growth (Kotovich et al., 2015).

\section{Conclusions and perspectives}

We used computed tomography X-ray imaging to quantify air inclusion distribution in sea ice, from which we derive the air volume fraction. Air inclusions are quickly and easily identified by X-ray tomography and quantitatively analyzed using segmentation techniques. The threshold selection is a crucial step requiring careful examination to provide successful results. The results from the CT X-ray analysis showed similar trends to conventional density and bulk ice total gas content ( $\mathrm{mL} \mathrm{L}^{-1}$ ice) measurement methods. X-ray imaging is non-destructive and allows for a direct determination of air inclusions in sea ice at high resolution with low errors and creates large data sets very quickly. However, the ability of the medical CT-scan to resolve air inclusions in columnar sea ice is limited since accurate definition of air inclusion in columnar sea ice would require higher resolution. Further studies should involve Micro-Ct scan with pixel size of 1 order of magnitude smaller.

We differentiate between micro bubbles, large bubbles, and macro bubbles based on their diameters. Micro bubbles are found both in the bottom columnar permeable layers $\left(V_{\mathrm{b}}>5 \%\right)$ and in the intermediate columnar impermeable layers $\left(V_{\mathrm{b}}<5 \%\right)$ as well as in granular layers. Large bubbles are found more frequently where brine volume exceeded $5 \%$, and macro bubbles occur exclusively in the granular snow ice layer (i.e., ice formed by the infiltration of snow) nearest the ice-atmosphere interface. Although micro bubbles are the most abundant type of bubbles observed, they only accounted for $14 \%$ of the total air volume fraction produced. In contrast, macro bubbles linked to granular snow ice layer accounted for $1 \%$ of the total number of bubbles but they produced $29 \%$ of the air volume fraction observed. While the air volume fraction results from a mix of micro, large and, macro bubbles, the factor controlling the air volume fraction is most likely the size of the air inclusions (i.e., bubbles) (Table 4).

We suggest that bubbles observed in the bottom subsaturated permeable layers are formed by convection-driven nucleation. Here the amount and size of the bubbles are limited by the low saturation state of the brine. Bubbles observed in impermeable columnar supersaturated sea ice are formed by solubility-driven nucleation, where the amount and bubble size is limited by the amount of brine. In growing sea ice, a maximum exists at a given depth just above the permeability transition, confirming the important role of this transition zone in shaping the vertical air volume fraction distribution. Macro bubbles located in the near-surface sea ice are linked to the presence of granular ice and the formation of snow ice (Table 6).

We conclude that processes regulating the vertical distribution of salts do not control the vertical distribution of gases, because most of the total gas content $\left(\mathrm{mL} \mathrm{L}^{-1}\right.$ ice) exists as bubbles rather than being dissolved in the brine as previously argued (Tison et al., 2002; Zhou et al., 2013; Moreau et al., 2014; Crabeck et al., 2014a, b). Once micro and/or macro bubbles form they are segregated from the transport pathway of dissolved salts, because bubbles will not drain out of the ice by convection due to their low density, so nucleation leads to an accumulation of gas in sea ice. Our work provides the first detailed visual demonstration and quantification of these processes.

As a result of the presence of large bubbles and higher air volume fraction measurements in sea ice we introduce new perspectives on processes regulating gas exchange at the ice-atmosphere interface, and note that further work should investigate the effect of air volume fraction on sea ice permeability parameterizations. CT-X-ray imaging may allow for visualizations of transport pathways, for example the upward migration of bubbles. CT-X-ray imaging could be used to investigate the effect of different thermal and crystal texture regimes on bubble formation, dimensions, and their vertical and horizontal distribution in a large number of replicate cores from the same ice cover. This information is vital to the improvement of models involving transport of biochemical compounds and gas transfer between the ocean and the atmosphere in polar oceans.

Acknowledgements. We gratefully acknowledge the contributions of the Canada Excellence Research Chair (CERC) and Canada Research Chair (CRC) programs. Support was also provided by the Natural Sciences and Engineering Research Council (NSERC), the Canada Foundation for Innovation, and the University of Manitoba. R. J. Galley thanks the NSERC discovery grant program. B. Delille is a research associate of the Fonds de la Recherche Scientifique - FNRS (Belgium). This work is a contribution to the ArcticNet Networks of Centres of Excellence and the Arctic Science Partnership (ASP) asp-net.org. This work is also a contribution to the BIGSOUTH project funded by the Belgian Science Federal Policy Office, and FNRS project 2.4517.11.

Edited by: M. Schneebeli

\section{References}

Bennington, K. O.: Desalination features in natural sea ice, J. Glaciol., 6, 845-857,1967.

Bock, C. and Eicken, H.: A magnetic resonance study of temperature-dependent microstructural evolution and selfdiffusion of water in Arctic first-year sea ice, Ann. Glaciol., 40, 179-184, 2005.

Carte, A. E.: Air bubbles in ice, Proc. Phys. Soc., 77, 757-768, 1961. 
Cole, D. M. and Shapiro, L. H.: Observations of brine drainage networks and microstructure of first-year sea ice, J. Geophys. Res., 103, 21739-21750, 1998.

Cole, D. M., Eicken, H., Frey, K., and Shapiro, L. H.: Observations of banding in first-year Arctic sea ice, J. Geophys. Res., 109, C08012, doi:10.1029/2003JC001993, 2004.

Cox, G. F. N. and Weeks, W. F.: Brine drainage and initial salt entrapment in sodium chloride ice, Report 345, Cold Regions Research and Engineering Laboratory Research, Hanover, NH, 1975.

Cox, G. F. N. and Weeks, W. F.: Equations for determining the gas and brine volumes in sea-ice samples, J. Glaciol., 29, 306-316, 1983.

Cox, G. F. N. and Weeks, W. F.: Changes in the salinity and porosity of sea-ice samples during shipping and storage, J. Glaciol., 32, $371-375,1986$.

Cox, G. F. N. and Weeks, W. F.: Numerical simulations of the profile properties of undeformed first-year sea ice during the growth season, J. Geophys. Res.-Oceans, 93, 12449-12460, 1988.

Crabeck, O., Delille, B., Else,.B, Thomas, D. N., Geilfus, N. X., Rysgaard, S., and Tison, J. L.: First "in situ" determination of gas transport coefficients $\left(\mathrm{DO}_{2}, \mathrm{DAr}\right.$, and $\left.\mathrm{DN}_{2}\right)$ from bulk gas concentration measurements $\left(\mathrm{O}_{2}, \mathrm{~N}_{2}, \mathrm{Ar}\right)$ in natural sea ice, J. Geophys. Res.-Oceans, 119, 6655-6668, doi:10.1002/2014JC009849, 2014a.

Crabeck, O., Delille, B., Thomas, D., Geilfus, N.-X., Rysgaard, S., and Tison, J.-L.: $\mathrm{CO}_{2}$ and $\mathrm{CH}_{4}$ in sea ice from a subarctic fjord under influence of riverine input, Biogeosciences, 11, 6525-6538, doi:10.5194/bg-11-6525-2014, 2014b.

Delille, B., Vancoppenolle, M., Geilfus, N.-X., Tilbrook, B., Lannuzel, D., Schoemann, V., Becquevort, S., Carnat, G., Delille, D., Lancelot, C., Chou, L., Dieckmann, G. S., and Tison, J.-L.: Southern Ocean $\mathrm{CO}_{2}$ sink: The contribution of the sea ice, J. Geophys. Res.-Oceans, 119, 6340-6355, doi:10.1002/2014JC009941, 2014.

Deutscher, R. L. and Fletcher, S.: Nucleation of Active Sites: 5. The Theory of Nucleation Rate Dispersion, J. Electroanalyt. Chem., 277, 1-18, 1990.

Duliu, O. G.: Computer axial tomography in geosciences: An overview, Earth-Sci. Rev., 48, 265-281, 1999.

Eicken, H., Lange, M. A., and Dieckmann, G. S.: Spatial Variability of Sea-Ice Properties in the Northwestern Weddell Sea, J. Geophys. Res., 96, 10603-10615, 1991.

Eicken, H., Bock, C., Wittig, R., Miller, H., and Poertner, H.-O.: Magnetic resonance imaging of sea-ice pore fluids: methods and thermal evolution of pore microstructure, Cold Reg. Sci. Technol., 31, 207-225, 2000.

Eide, L. I. and Martin, S.: The formation of brine drainage features in young sea ice, J. Glaciol., 14, 137-154, 1975.

Feltham, D. L., Untersteiner, N., Wettlaufer, J. S., and Worster, M. G.: Sea ice is a mushy layer, Geophys. Res. Lett., 33, L14501, doi:10.1029/2006GL026290, 2006.

Fritsen, C. H., Lytle, V. I., Ackley, S. F., and Sullivan, C. W.: Autumn bloom of Antarctic pack-ice algae, Science, 266, 782-784, 1994.

Galley, R. J., Else, B. G. T., Geilfus, N.-X., Hare, A. A., Isleifson, D., Barber, D. G., and Rysgaard, S.: Imaged brine inclusion in young sea ice - Shape, distribution and formation timing, Cold Reg. Sci. Technol., 111, 39-48, doi:10.1016/j.coldregions.2014.12.011, 2015.

Garcia, H. E. and Gordon, L. I.: Oxygen solubility in seawater - better fitting equations, Limnol. Oceanogr., 37, 1307-1312, 1992.

Geilfus, N.-X., Carnat, G., Dieckmann, G. S., Halden, N., Nehrke, G., Papakyriakou, T., Tison, J. L., and Delille, B.: First estimates of the contribution of $\mathrm{CaCO}_{3}$ precipitation to the release of $\mathrm{CO}_{2}$ to the atmosphere during young sea ice growth, J. Geophys. Res.Oceans, 118, 244-255, 2013.

Geilfus, N.-X., Tison, J.-L., Ackley, S. F., Rysgaard, S., Miller, L. A., and Delille, B.: Sea ice $p \mathrm{CO}_{2}$ dynamics and air-ice $\mathrm{CO}_{2}$ fluxes during the Sea Ice Mass Balance in the Antarctic (SIMBA) experiment - Bellingshausen Sea, Antarctica, The Cryosphere, 8, 2395-2407, doi:10.5194/tc-8-2395-2014, 2014.

Geilfus, N.-X., Galley, R. J., Crabeck, O., Papakyriakou, T., Landy, J., Tison, J.-L., and Rysgaard, S.: Inorganic carbon dynamics of melt-pond-covered first-year sea ice in the Canadian Arctic, Biogeosciences, 12, 2047-2061, doi:10.5194/bg-12-2047-2015, 2015.

Golden, K. M., Ackley, S. F., and Lytle, V. I.: The percolation phase transition in sea ice, Science, 282, 2238-2241, 1998.

Golden, K. M., Eicken, H., Heaton, A. L., Miner, J., Pringle, D. J., and Zhu, J.: Thermal evolution of permeability and microstructure in sea ice, Geophys. Res. Lett., 34, L16501, doi:10.1029/2007GL030447, 2007.

Grasshoff, K., Erhard, M., and Kremling, K.: Methods of seawater analysis, 2nd Edn., Verlag-Chemie, Weinhem, Germany, 1983.

Grenfell, T. C.: A theoretical model of the optical properties of sea ice in the visible and near infrared, J. Geophys. Res., 88, 97239735, 1983.

Hamme, R. C. and Emerson, S. R.: The solubility of neon, nitrogen and argon in distilled water and seawater, Deep-Sea Res. Pt. I, 51, 1517-1528, 2004.

Hare, A. A., Wang, F., Barber, D., Geilfus, N.-X., Galley, R. J., and Rysgaard, S.: $\mathrm{pH}$ evolution in sea ice grown at an outdoor experimental facility, Mar. Chem., 154, 46-54, doi:10.1016/j.marchem.2013.04.007, 2013.

Hounsfield, G. N.: Computerized transverse axial scanning (tomography). Part 1: Description of system, British J. Radiol., 46, 1016-1022, 1973.

Hunter, M. W., Dykstra, R., Lim, M. H., Haskell, T. G., and Callaghan, P. T.: Using Earth's field NMR to study brine content in Antarctic sea ice: Comparison with salinity and temperature estimates, Appl. Magnet. Reson., 36, 1-8, doi:10.1007/s00723009-0003-9, 2009.

Iassonov, P., Gebrenegus, T., and Tuller, M.: Segmentation of X-ray computed tomography images of porous materials: A crucial step for characterization and quantitative analysis of pore structures, Water Resour. Res., 45, W09415, doi:10.1029/2009WR008087, 2009.

Kapur, J. N., Sahoo, P. K., and Wong, A. K. C.: A new method for gray-level picture thresholding using the entropy of the histogram, Graph. Models Image Process., 29, 273-285, doi:10.1016/0734-189X(85)90125-2, 1985.

Kawamura, T. :Observations of the internal structure of sea ice by $\mathrm{X}$ ray computed tomography, J. Geophys. Res., 93, 2343-2350, doi:10.1029/JC093iC03p02343, 1988.

Killawee, J. A., Fairchild, I. J., Tison, J. L., Janssens, L., and Lorrain, R.: Segregation of solutes and gases in experimental freez- 
ing of dilute solutions: Implications for natural glacial systems, Geochim. Cosmochim. Acta, 62, 3637-3655, 1998.

Knoll, G. F.: Radiation Detection and Measurment, John Wiley \& Sons, New York, 1989.

Kotovitch, M., Moreau, S., Zhou, J., Vancoppenolle, M., Dieckmann, G. S., Evers, K.-U., Van der Linden, F., Thomas, D. N., Tison, J.-L., and Delille, B.: Air-ice carbon pathways inferred from a sea ice tank experiment, J. Elementa, accepted, 2015.

Kozisek, Z., Demo, P., and Sato, K.: Nucleation on active sites: Evolution of size distribution, J. Cryst. Growth, 209, 198-202, 2000.

Krembs, C., Gradinger, R., and Spindler, M.: Implications of brine channel geometry and surface area for the interaction of sympagic organisms in Arctic sea ice, J. Exp. Mar. Biol. Ecol., 243, 55-80, 2000.

Langway, C. C.: Ice fabrics and the universal stage Rep. 62, US Snow, Ice and 496 Permafrost Research Establishment, Wilmette, Illinois, 1958.

Light, B., Maykut, G. A., and Grenfell, T. C.: Effects of temperature on the microstructure of first-year Arctic sea ice, J. Geophys. Res., 108, 3051, doi:10.1029/2001JC000887, 2003.

Loose, B., McGillis, W. R., Schlosser, P., Perovich, D., and Takahashi, T.: Effects of freezing, growth, and ice cover on gas transport processes in laboratory seawater experiments, Geophys. Res. Lett., 36, L05603, doi:10.1029/2008g1036318, 2009.

Loose, B., Schlosser, P., Perovich, D., Ringelberg, D., Ho, D. T., Takahashi, T., Richter-Menge, J., Reynolds, C. M., McGillis, W. R., and Tison, J. L.: Gas diffusion through columnar laboratory sea ice: implications for mixed-layer ventilation of $\mathrm{CO}_{2}$ in the seasonal ice zone, Tellus B, 63, 23-39, doi:10.1111/j.16000889.2010.00506.x, 2011.

Lubetkin, S. D.: Why is it much easier to nucleate gas bubbles than theory predicts?, Langmuir, 19, 2575-2587, 2003.

Matsuo, S. and Miyake, Y.: Gas composition in ice samples from Antarctica, J. Geophys. Res., 71, 5235-5241, 1966.

Moreau, S., Vancoppenolle, M., Zhou, J., Tison, J.-L., Delille, B., and Goosse, H.: Modelling argon dynamics in first-year sea ice, Ocean Model., 73, 1-18, 2014.

Nomura, D., Yoshikawa-Inoue, H., and Toyota, T.: The effect of seaice growth on air-sea $\mathrm{CO}_{2}$ flux in a tank experiment, Tellus $\mathrm{B}, 58$, 418-426, 2006.

Nomura, D., Yoshikawa-Inoue, H., Toyota, T., and Shirasawa, K.: Effects of snow, snow-melting and re-freezing processes on airsea ice $\mathrm{CO}_{2}$ flux, J. Glaciol., 56, 262-270, 2010.

Nomura, D., Yoshikawa-Inoue, H., Kobayashi, S., Nakaoka, S., Nakata, K., and Hashida, G.: Winter-to-summer evolution of $p \mathrm{CO}_{2}$ in surface water and air-sea $\mathrm{CO}_{2}$ flux in the seasonal ice zone of the Southern Ocean, Biogeosciences, 11, 5749-5761, doi:10.5194/bg-11-5749-2014, 2014.

Notz, D. and Worster, M. G.: In situ measurements of the evolution of young sea ice, J. Geophys. Res., 113, C03001, doi:10.1029/2007JC004333, 2008.

Obbard, R., Troderman, G., and Baker, I.: Imaging brine and air inclusions in sea ice using micro-X-ray computed tomography, correspondance, J. Glaciol., 55, 1113-1115, 2009.

Otsu, N.: A threshold selection method from gray-level histograms, IEEE Trans. Syst. Man Cybern., 9, 62-66, doi:10.1109/TSMC.1979.4310076, 1979.

Pal, N. R.: Minimum cross entropy threshold selection, Pattern Recog., 29, 575-580, doi:10.1016/0031-3203(95)00111-5, 1996.
Pal, N. R., and Pal, S. K.: Entropic thresholding, Signal Process., 16, 97-108, doi:10.1016/0165-1684(89)90090-X, 1989.

Perovich, D. K. and Gow, A. J.: A statistical description of the microstructure of young sea ice, J. Geophys. Res., 96, 1694316953, doi:10.1029/91JC01594, 1991.

Perovich, D. K. and Gow, A. J.: A quantitative description of sea ice inclusions, J. Geophys. Res.- Oceans, 101, 18327-18343, 1996.

Pringle, D. J., Miner, J. E., Eicken, H., and Golden, K. M.: Pore space percolation in sea ice single crystals, J. Geophys. Res., 114, C12017, doi:10.1029/2008JC005145, 2009.

Raynaud, D., Delmas, R., Ascencio, M., and Legrand, M.: Gas extraction from polar ice cores: a critical issue for studying the evolution of atmospheric $\mathrm{CO}_{2}$ and ice-sheet surface elevation, Ann. Glaciol., 3, 265-268, 1982.

Rees Jones, D. W. and Worster, M. G.: A simple dynamical model for gravity drainage of brine from growing sea ice, Geophys. Res. Lett., 40, 1-5, doi:10.1029/2012GL054301, 2013.

Ridler, T. W. and Calvard, S.: Picture thresholding using an iterative selection method, IEEE Trans. Syst. Man Cybern., 8, 630-632, 1978.

Rosin, P. L.: Unimodal thresholding, Pattern Recog., 34, 20832096, doi:10.1016/S0031-3203(00)00136-9,1978, 2001.

Rysgaard, S. and Glud, R. N.: Anaerobic $\mathrm{N}_{2}$ production in Arctic sea ice, Limnol. Oceanogr., 49, 86-94, 2004.

Rysgaard, S., Wang, F., Galley, R. J., Grimm, R., Notz, D., Lemes, M., Geilfus, N.-X., Chaulk, A., Hare, A. A., Crabeck, O., Else, B. G. T., Campbell, K., Sørensen, L. L., Sievers, J., and Papakyriakou, T.: Temporal dynamics of ikaite in experimental sea ice, The Cryosphere, 8, 1469-1478, doi:10.5194/tc-8-14692014, 2014.

Semiletov, I. P., Makshtas, A., Akasofu, S. I., and Andreas, E. L.: Atmospheric $\mathrm{CO}_{2}$ balance: The role of Arctic sea ice, Geophys. Res. Lett., 31, L05121, doi:10.1029/2003GL017996, 2004.

Sezgin, M. and Sankur, B.: Survey over image thresholding techniques and quantitative performance evaluation, J. Electron. Imaging, 13, 146-165, doi:10.1117/1.1631315, 2004.

Shannon, C. E. and Weaver, W.: The mathematical theory of communication, Bell Syst. Tech. J., 27, 379-423, 1948.

Skoog, D. A., West, D. M., and Holler, F. J.: Chimie Analytique, De Boeck Univ., Paris, 1997.

Stefels, J., Carnat, G., Dacey, J. W. H., Goossens, T., Elzenga, J. T. M., and Tison, J. L.: The analysis of dimethylsulfide and dimethylsulfoniopropionate in sea ice: Dry-crushing and melting using stableisotope additions, Mar. Chem., 128-129, 34-43, 2012.

Timco, G. W. and Frederking, R. M. W.: A review of sea ice density, Cold Reg. Sci. Technol., 24, 1-6, 1996.

Tison, J. L., Haas, C., Gowing, M. M., Sleewaegen, S., and Bernard, A.: Tank study of physico-chemical controls on gas content and composition during growth of young sea ice, J. Glaciol., 48, 177191, 2002.

Tison, J.-L., Worby, A., Delille, B., Brabant, F., Papadimitriou, S., Thomas, D., de Jong, J., Lannuzel, D., and Haas, C.: Temporal evolution of decaying summer first-year sea ice in the Western Weddell Sea, Antarctica, Deep-Sea Res. Pt. II, 55, 975-987, 2008.

Tsai, D. M.: A fast thresholding selection procedure for multimodal and unimodal histograms, Pattern Recog. Lett., 16, 653-666, doi:10.1016/0167-8655(95)80011-H, 1995. 
Tsurikov, V. :The formation and composition of the gas content of sea ice, J. Glaciol., 22, 67-81, 1979.

UNESCO: Eight report of the joint panel on oceanographic tables and standards, UNESCO Tech. Pap. Mar. Sci., Paris, France, 28 pp., 1978.

Vancoppenolle, M., Meiners, K. M., Michel, C., Bopp, L., Brabant, F., Carnat, G., Delille, B., Lannuzel, D., Madec, G., Moreau, S., Tison, J.-L., and van der Merwe, P.: Role of sea ice in global biogeochemical cycles: Emerging views and challenges, Quaternary Sci. Rev., 79, 207-230, doi:10.1016/j.quascirev.2013.04.011, 2013.

Weeks, W. F. and Ackley, S. F.: The growth, structure and properties of sea ice, in: The geophysics of sea ice, edited by: Untersteiner, N., Plenum Press, New York, 9-164, 1986.

Wilt, P. M.: Nucleation rates and bubble stability in watercarbon dioxide solutions, J. Colloid Interf. Sci., 112, 530-538, doi:10.1016/0021-9797(86)90122-0, 1986.

Worster, M. G.: The dynamics of mushy layers, in: Interactive Dynamics of Convection and Solidification, NATO ASI Ser. E219, Kluwer, Dordrecht, 113-138, 1992.
Worster, M. G.: Convection in mushy layers, Annu. Rev. Fluid Mech., 29, 91-122, 1997.

Yen, J.-C., Chang, F. J., and Chang, S.: A new criterion for automatic multilevel thresholding, IEEC Trans. Image Process., 4, 370-378, doi:10.1109/83.366472, 1995.

Zack, G. W., Rogers, W. E., and Latt, S. A.: Automatic measurement of a sister chromatid exchange frequency, J. Histochem. Cytochem., 25, 741-753, 1997.

Zemmelink, H. J., Delille, B., Tison, J. L., Hintsa, E. J., Houghton, L., and Dacey, J. W. H.: $\mathrm{CO}_{2}$ deposition over the multi-year ice of the western Weddell Sea, Geophys. Res. Lett., 33, L13606, doi:10.1029/2006GL026320, 2006.

Zhou, J. Y., Delille, B., Eicken, H., Vancoppenolle, M., Brabant, F., Carnat, G., Geilfus, N. X., Papakyriakou, T., Heinesch, B., and Tison, J. L.: Physical and biogeochemical properties in landfast sea ice (Barrow, Alaska): Insights on brine and gas dynamics across seasons, J. Geophys. Res.-Oceans, 118, 3172-3189, doi:10.1002/jgrc.20232, 2013. 